\title{
Helicopter Flight Test of a Compact, Real-Time 3-D Flash Lidar for Imaging Hazardous Terrain during Planetary Landing
}

\author{
Vincent E. Roback ${ }^{1}$, Farzin Amzajerdian ${ }^{3}$, Paul F. Brewster ${ }^{4}$, Bruce W. Barnes ${ }^{5}$, Kevin S. Kempton ${ }^{6}$, and Robert A. \\ Reisse $^{7}$ \\ NASA-Langley Research Center, Hampton, Virginia, 23681 \\ Alexander E. Bulyshev ${ }^{2}$ \\ Analytical Mechanics Associates, Inc., Hampton, Virginia, 23666
}

\begin{abstract}
A second generation, compact, real-time, air-cooled 3-D imaging Flash Lidar sensor system, developed from a number of cutting-edge components from industry and NASA, is lab characterized and helicopter flight tested under the Autonomous Precision Landing and Hazard Detection and Avoidance Technology (ALHAT) project. The ALHAT project is seeking to develop a guidance, navigation, and control (GN\&C) and sensing system based on lidar technology capable of enabling safe, precise crewed or robotic landings in challenging terrain on planetary bodies under any ambient lighting conditions. The Flash Lidar incorporates a 3-D imaging video camera based on Indium-Gallium-Arsenide Avalanche Photo Diode and novel micro-electronic technology for a $128 \times 128$ pixel array operating at a video rate of $20 \mathrm{~Hz}$, a high pulse-energy $1.06 \mu \mathrm{m}$ Neodymium-doped: Yttrium Aluminum Garnet (Nd:YAG) laser, a remote laser safety termination system, high performance transmitter and receiver optics with one and five degrees field-of-view (FOV), enhanced onboard thermal control, as well as a compact and self-contained suite of support electronics housed in a single box and built around a PC-104 architecture to enable autonomous operations. The Flash Lidar was developed and then characterized at two NASA-Langley Research Center (LaRC) outdoor laser test range facilities both statically and dynamically, integrated with other ALHAT GN\&C subsystems from partner organizations, and installed onto a Bell UH-1H Iroquois "Huey" helicopter at LaRC. The integrated system was flight tested at the NASA-Kennedy Space Center (KSC) on simulated lunar approach to a custom hazard field consisting of rocks, craters, hazardous slopes, and safe-sites near the Shuttle Landing Facility runway starting at slant ranges of $750 \mathrm{~m}$. In order to evaluate different methods of achieving hazard detection, the lidar, in conjunction with the ALHAT hazard detection and GN\&C system, operates in both a narrow $1^{\circ} \mathrm{FOV}$ raster-scanning mode in which successive, gimbaled images of the hazard field are mosaicked together as well as in a wider, $4.85^{\circ}$ FOV staring mode in which digital magnification, via a novel 3-D superresolution technique, is used to effectively achieve the same spatial precision attained with the more narrow FOV optics. The lidar generates calibrated and corrected 3-D range images of the hazard field in real-time and passes them to the ALHAT Hazard Detection System (HDS) which stitches the images together to generate on-the-fly Digital Elevation
\end{abstract}

${ }^{1}$ Remote Sensing Flight Systems Branch, M/S 468, NASA-Langley, Hampton, Virginia 23681, AIAA senior member.

${ }^{2}$ Analytical Mechanics Associates, Inc., 21 Enterprise Parkway, Hampton, Virginia 23666.

${ }^{3}$ Laser Remote Sensing Branch, M/S 468, NASA-Langley, Hampton, Virginia 23681.

${ }^{4}$ Flight Software Systems Branch, M/S 472, NASA-Langley, Hampton, Virginia 23681.

${ }^{5}$ Laser Remote Sensing Branch, M/S 468, NASA-Langley, Hampton, Virginia 23681.

${ }^{6}$ Flight Software Systems Branch, M/S 472, NASA-Langley, Hampton, Virginia 23681.

${ }^{7}$ Flight Projects Directorate, M/S 494, NASA-Langley, Hampton, Virginia 23681. 


\begin{abstract}
Maps (DEM's) and identifies hazards and safe-landing sites which the ALHAT GN\&C system can then use to guide the host vehicle to a safe landing on the selected site. Results indicate that, for the KSC hazard field, the lidar operational range extends from $100 \mathrm{~m}$ to $1.35 \mathrm{~km}$ for a 30 degree line-of-sight angle and a range precision as low as $8 \mathrm{~cm}$ which permits hazards as small as $25 \mathrm{~cm}$ to be identified. Based on the Flash Lidar images, the HDS correctly found and reported safe sites in near-real-time during several of the flights. A follow-on field test, planned for 2013, seeks to complete the closing of the GN\&C loop for fully-autonomous operations on-board the Morpheus robotic, rocket-powered, free-flyer test bed in which the ALHAT system would scan the KSC hazard field (which was vetted during the present testing) and command the vehicle to landing on one of the selected safe sites.
\end{abstract}

\title{
I. Introduction
}

L anding mission concepts being developed for the exploration of planetary bodies increasingly require precision landings on sites of high scientific value making on-board, real-time terrain hazard detection and avoidance capabilities a necessity. Future human exploration missions will similarly require precision landing with increased levels of safety over those performed in the Apollo program if they are to become more commonplace. Despite the successes of the Apollo program, which was constrained to land under favorable lighting conditions at sites with no significant terrain challenges, two of the six missions experienced near disaster during the landing phase with all six landings described as being perilous ${ }^{1}$. As an example, Fig. 1 shows that Apollo 15 landed partially in a crater which resulted in a crumpled main engine bell and a vehicle resting attitude near the safe limit. Due to its ability to provide three-dimensional (3-D) images of surfaces and hazards for future robotic and crewed landing missions to planetary bodies including the moon, Mars, asteroids, etc., the imaging Flash Lidar is being evaluated for use as the primary landing system sensor.

An imaging Flash Lidar system records a 3-D image of a scene by converting intensity versus time of flight of short laser pulses into intensity versus distance along the line of sight for each spatially resolved area within a twodimensional (2-D) image. In older, more conventional imaging lidar systems, each 2-D pixel is recorded with a separate laser pulse. Thus many laser pulses are required to record large, multi-pixel images. A Flash Lidar system records full 3-D images with a single laser pulse, permitting higher data rates and freezing out movement within the scene and motion of the transmitter/receiver platform. The need for high speed raster scanners to sequentially address image pixels is also

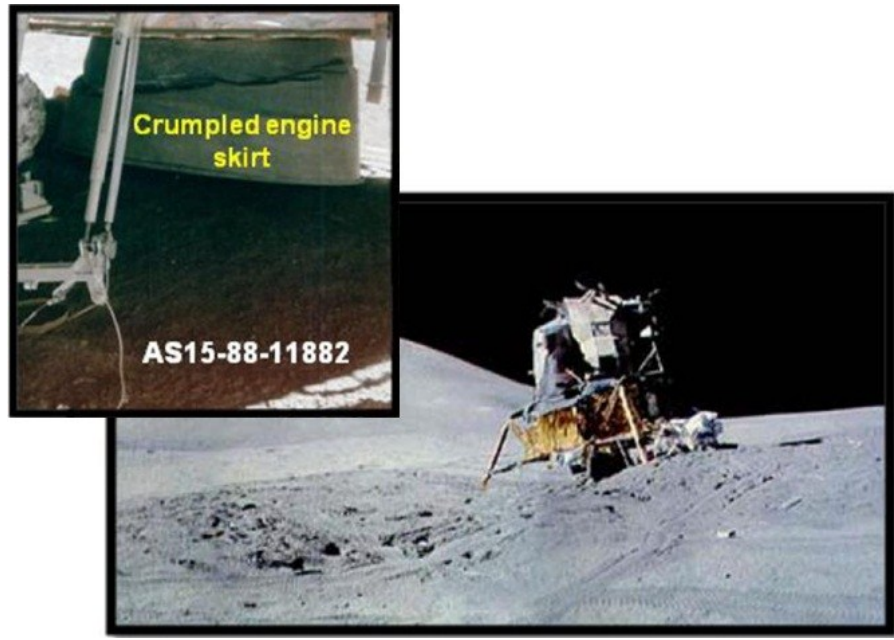

Figure 1. Apollo 15 landed partially in a crater which crumpled its main engine nozzle bell and left the vehicle in a resting attitude near its safe limit ${ }^{1}$.

eliminated. The receiver is much like the familiar digital camera, but with "smart pixels" that are capable of recording the required sequential temporal information. The NASA-Langley Research Center (LaRC) has been incorporating the latest Flash Lidar technologies into an operational landing sensor under the Autonomous Precision Landing and Hazard Detection and Avoidance Technology (ALHAT) project. The ALHAT project, led by NASA Johnson Space Center, was established by NASA to develop and demonstrate a guidance, navigation, and control system for future planetary landing missions capable of terrain hazard avoidance (see Fig. 2) and precision landing under any lighting conditions anywhere on the body ${ }^{2}$. 
To meet the requirements of providing global access to a planetary body under any lighting conditions, ALHAT is pursuing active sensor technology development and maturation to implement the following sensor functions: altimetry, velocimetry, Terrain Relative Navigation (TRN), Hazard Detection and Avoidance (HDA) and Hazard Relative Navigation (HRN). Table 1 lists the Flash Lidar's top level performance specifications for achieving each of required functions with some degree of redundancy. The correlation between desired resolution (i.e. minimum resolvable hazard size) and the needed range precision has been previously reported ${ }^{3}$. In addition to the range precision requirement, a Ground Sample Distance (GSD) of $10 \mathrm{~cm}$ is needed in order to achieve the Table 1 hazard resolution ${ }^{3}$.

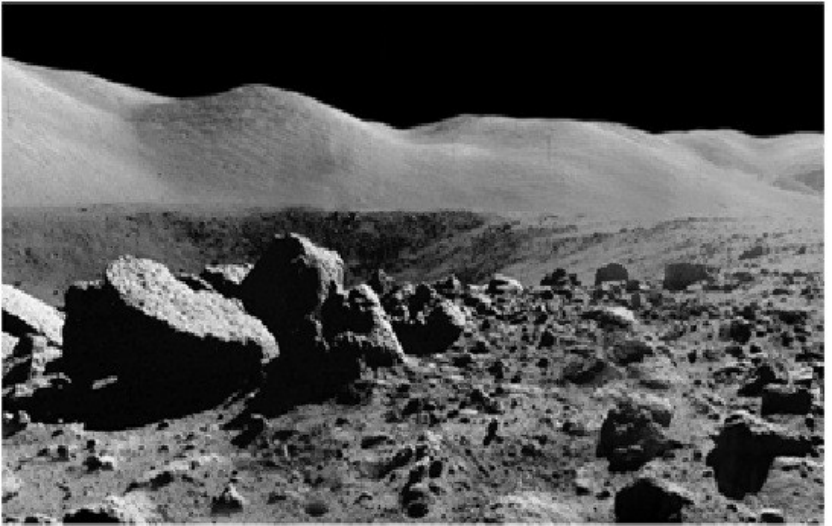

Figure 2. Future planetary landing missions (moon shown here) are considering scientifically interesting sites near craters and rough terrain.

GSD is the ground footprint of one pixel on a target at normal incidence and can be thought of as spatial precision. The GSD and range precision levels required are intuitively clear since measurement precision must generally be several times better than the minimum desired quantity to be measured (which, in the present case, is an image range variation which points to the presence of a hazard). The Flash Lidar is being considered for performing all of the required sensor functions with the exception of velocimetry for which a Doppler Lidar is being developed ${ }^{4,5}$. The Laser Altimeter provides independent altitude data over a large operational altitude range of $20 \mathrm{~km}$ to $100 \mathrm{~m}$. All three laser sensors have a nominal update rate of $30 \mathrm{~Hz}$. The manner in which the three ALHAT lidar sensors are utilized to achieve the required sensor functions is reported elsewhere ${ }^{6}$.

All of the aforementioned landing measurement functions provide input to the navigation filter for the landing vehicle's state estimation, flight trajectory retargeting, and maneuvering to a safe site. Of these five functions, altimetry and velocimetry are direct sensor measurements, whereas the TRN, HDA, and HRN functions can be considered relative measurements, since the sensor output is derived from a correlation with either "a priori" terrain information, or with a sequence of previous sensor measurements. The

Table 1. Flash Lidar performance goals.

\begin{tabular}{|l|l|l|}
\hline Function & Operational Altitude Range & Precision/Resolution \\
\hline HDA/HRN & $1000 \mathrm{~m}-100 \mathrm{~m}$ & $5 \mathrm{~cm} / 30 \mathrm{~cm}$ \\
\hline TRN & $15 \mathrm{~km}-5 \mathrm{~km}$ & $20 \mathrm{~cm} / 6 \mathrm{~m}$ \\
\hline Altimetry & $20 \mathrm{~km}-100 \mathrm{~m}$ & $20 \mathrm{~cm}$ \\
\hline
\end{tabular}

latter functions can also be considered techniques, since a number of sensor / algorithm combinations can achieve similar results under the appropriate concept of operation. The location determination of safe landing sites is made based on the location of detected hazards which are simultaneously recorded within the 3-D images in complete spatial and temporal resolution. The recording of full 3-D scenes with single laser pulses not only enables more rapid acquisition, but simpler and more rapid processing of scene information. At a high refresh rate, this information enables the time-sensitive precision navigation necessary to avoid hazards and land precisely at the retargeted location. 
In the current ALHAT operational concept (Fig. 3), the Flash Lidar serves as a multi-function sensor capable of providing many of the needed ALHAT measurement functions. The concept incorporates a Flash Lidar system capable of generating 256x256 pixel image frames from nominally a one kilometer distance. The POST-2 simulation has been utilized extensively to optimize the ALHAT Guidance, Navigation, and Control (GN\&C) architecture, sensor algorithms, and sensor hardware. The Flash Lidar initiates its operation in an altimetry mode after the vehicle begins its breaking phase and its altitude drops to approximately $20 \mathrm{~km}$ above the ground. In the altimetry mode of operation, the lidar transmitter laser is focused such that only a few of the detector array pixels are illuminated. The focusing of the laser increases the operational range of the lidar from one kilometer (with all of its pixels illuminated) to $20 \mathrm{~km}$ (with only about 100 illuminated pixels). The range data is then provided to the vehicle's flight computer to improve its relative position estimate to the surface from more than $1 \mathrm{~km}$ to approximately $300 \mathrm{~m}$.

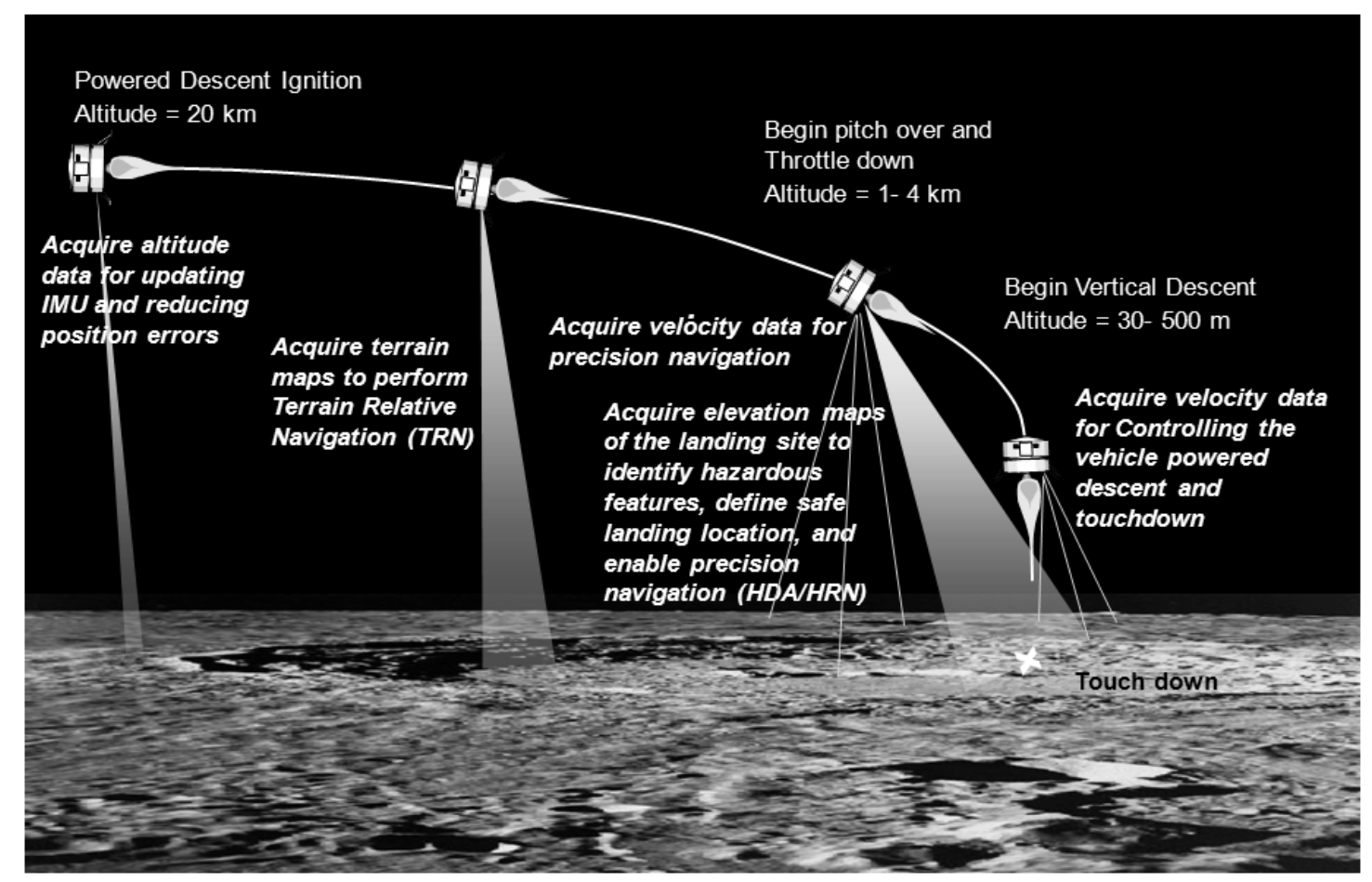

Figure 3. Operational scenario of landing sensors.

At approximately $15 \mathrm{~km}$ above ground level, the Flash Lidar will switch to the TRN mode (which has been previously reported ${ }^{7}$ ) by slightly increasing the transmitter beam divergence to illuminate approximately 200 pixels. In this mode, the Flash Lidar will continue to provide altitude data as well as generating consecutive 3-D images of the terrain with a lateral resolution of less than six meters which is sufficient for performing the TRN function. The resulting digital elevation maps created from the acquired images are correlated with stored on-board reference maps of known features such as craters and surface elevation data. The correlations are used to estimate the relative position error (map-tie error) between the surface and the inertial frames of the vehicle. Correlation of the Flash Lidar data with the surface elevation data obtained from prior orbiting laser altimeters are particularly reliable in estimating the map-tie error, thereby enabling the TRN algorithm to generate the trajectory correction needed for bringing the vehicle to within 30 meters of the landing target. 

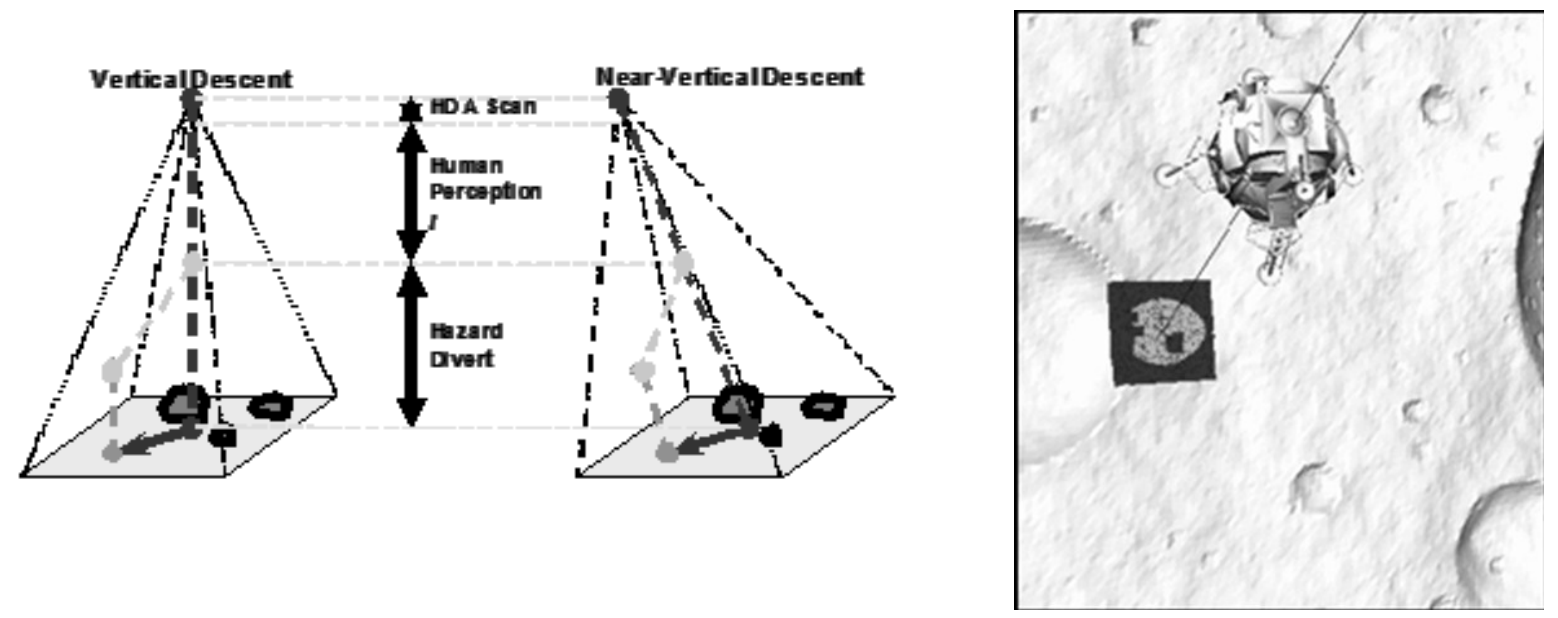

Figure 4. The hazard detection phase is expected to begin when the lander pitches over to start its approach descent to the surface. The slope of descent can be adjusted to allow for sensor field of view considerations and, if necessary, for human interaction.

After completion of the TRN function at approximately five kilometers above ground level, the Flash Lidar continues to provide altitude data to further reduce the navigation error. At approximately one kilometer in altitude, the laser beam divergence is increased to match the full field of view of the lidar receiver in preparation for the most critical function, HDA)/HRN. The HDA/HRN function requires detection of rocks and surface features greater than $30 \mathrm{~cm}$ in height, detection of slopes greater than $5^{0}$ over the diagonal of the footprint of the landing vehicle, and determination of landmark position to better than one meter relative to the specified landing location (see Fig. 4).

Various operational concepts for 3-D image acquisition are being evaluated. Each concept must provide the necessary information for achieving the ALHAT HDA/HRN performance goals and simultaneously provide situational awareness information. The primary metric for evaluating an operational concept is its robustness, i.e. how efficiently, accurately, and reliably the task is accomplished. In the context of ALHAT, robustness means that the operational concept must be fast, accurate, and be able to provide redundant information for real-time validation of decisions made to accomplish a safe landing.

An operational concept, similar to targeting, that employs some of the capabilities being developed, is termed intelligent safe site selection using precision navigation. Under intelligent safe site selection, HDA/HRN are coupled both in hardware and software since the processing used for determining hazard locations is also used for selecting and tracking landmarks for relative navigation. With the HDA/HRN coupling, both functions can be accomplished using the same sequence of 3-D images from the Flash Lidar. The HRN concept is based on the concept that upon recognition of the first available safe landing site, the vehicle is directed to it using vectors relative to a nearby landmark (which is likely a landing hazard, hence the term HRN). Continuous operation of the Flash Lidar down to approximately 100 meters above ground level allows for a high precision (1 meter) landing within the identified safe landing area. The continuous operation of Flash Lidar at video frame rates allows the determined safe location to be verified multiple times before the vehicle commits to a touch-down. To ensure that sufficient terrain area is in view throughout vehicle descent, since a fixed field of view (FOV) results in a smaller and smaller footprint as altitude decreases, an adjustable FOV receiver optic is being considered. By increasing the receiver FOV according to its distance to the ground, the spatial coverage and resolution are preserved.

The present field test of the ALHAT Guidance, Navigation, and Control (GN\&C) and sensing system integrated on a UH-1H helicopter, is the fifth field test (FT5) for the ALHAT project. FT5 marks the first time that the ALHAT system is integrated and tested with several sub-systems of the rocket-powered, robotic, free-flyer test bed (Morpheus) during a realistic landing trajectory. From the Flash Lidar standpoint, FT5 is focused on the HDA and HRN functions. Previous reporting ${ }^{7,8}$ has detailed the progression toward the ultimate goals as accomplished in each prior development and field test cycle for the Flash Lidar sensor (field tests one, three, and four with number two being devoted solely to the Doppler lidar). The present sensor development cycle achieved reductions in Flash Lidar power consumption, volume, and weight while improving reliability and safety. The air-cooled Flash Lidar system is capable of producing images in real-time during autonomous operations although the helicopter test did not permit a full demonstration of its autonomous functionality. Leading up to the helicopter field test, the full ALHAT system was integrated with key sub-systems of Morpheus in an instrumented truck for dynamic testing at a 
long-distance track which allowed the system to be operated over a large portion of flight ranges while imaging a target building on which are mounted several hazards and safe sites. During the helicopter field test, the helicopter with its integrated ALHAT and Morpheus sub-systems is flown on simulated lunar landing trajectories toward a custom hazard field consisting of rocks, craters, hazardous slopes, and pre-defined safe-sites. The 100 meter square hazard field was constructed at the North end of the Shuttle Landing Facility runway at the NASA-Kennedy Space Center (KSC). With minimal on-board operator intervention (only necessary in order to overcome the differences in the operational concept between the helicopter and Morpheus), the Flash Lidar produced calibrated and corrected images of the hazard field and passed them in real-time to the ALHAT Hazard Detection System (HDS). The HDS stitched together the $1^{\circ}$ FOV images in near-real-time into 3-D Digital Elevation Maps (DEM's) and then identified safe-sites from amongst the hazardous craters, rocks, and slopes ${ }^{9,10}$. Additionally, hazards were imaged using the staring (track-point) mode of the system with $4.85^{\circ}$ optics in place to provide datasets used to assess superresolution algorithms. The superresolution technique is a novel method to enhance the 3-D mapping precision using multiple images from a moving vehicle to make a 3-D image equivalent to the finer spatial precision possible with the more narrow $1^{\circ}$ optics via digital magnification ${ }^{11}$. Since the staring mode used for superresolution employs optics with approximately 5 times the FOV of the mosaicking mode, it does not require gimbal raster scanning coupled with careful stitching together of the raster-scanned images in order to cover the entire landing zone. Absent the need for raster scanning, the pointing and positioning knowledge requirements are significantly relaxed, making the superresolution technique potentially more robust. Additionally, since the staring, superresolution mode obviates the need for acquiring and stitching together images, it can potentially reduce latencies when providing critical data to the host vehicle. The helicopter field test provided the first in-flight opportunity to image the KSC hazard field with the Flash Lidar in order to evaluate effects of surface and hazard reflectivities on the Flash Lidar's operational range, dynamic range, and range precision performance in preparation for future fully-autonomous flights. The next field test will focus on closing the GN\&C loop through Morpheus free-flights in which the ALHAT system would direct Morpheus to safe-sites for actual landings on the same KSC hazard field.

\section{Lidar System Configuration}

The current Generation 2.2 (Gen 2.2) 3-D imaging Flash Lidar is a compact, real-time, air-cooled sensor system capable of autonomously imaging a target scene at video rates of $20 \mathrm{~Hz}$ with a $128 \times 128$ array of pixels that report not only intensity but range by sampling the roundtrip timing of an energy pulse from a class IV laser operating at $1.064 \mu \mathrm{m}$. The Flash Lidar sensor system consists of a Flash Lidar Sensor Head (FLSH), which is shown in Figure 5, and a Flash Lidar Electronics Box (LEB), which is shown in Figure 6. The size, weight, and operating power of the

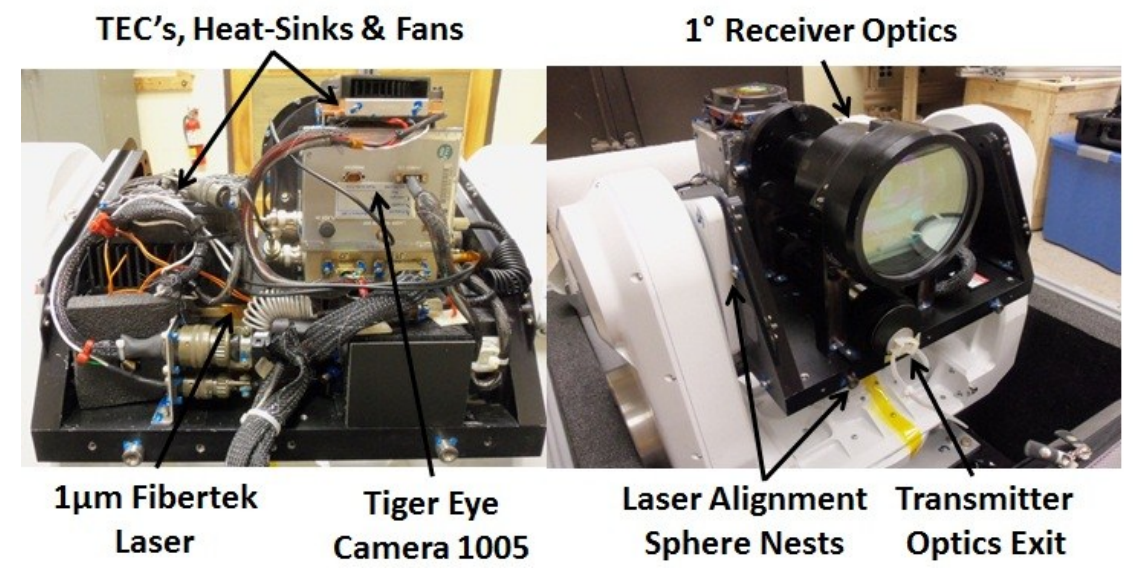

Figure 5. Gen 2.2 Flash Lidar Sensor Head (without aerodynamic shroud).

Gen 2.2 Flash Lidar are detailed in Table 2. The essential functional configuration of the system is the same for laboratory and flight testing. 
The sensor head consists of the laser optics module, a set of transmitter optics, a set of receiver optics, a 3-D imaging IR video camera, as well as supporting mechanical, electrical, and software components. The Gen 2.2 laser is a $1.064 \mu \mathrm{m}$, class IV (non-eye-safe), Neodymium: Yttrium Aluminum Garnet (Nd:YAG) Fibertek model with pulse characteristics detailed in Table 3. Note that the laser is capable
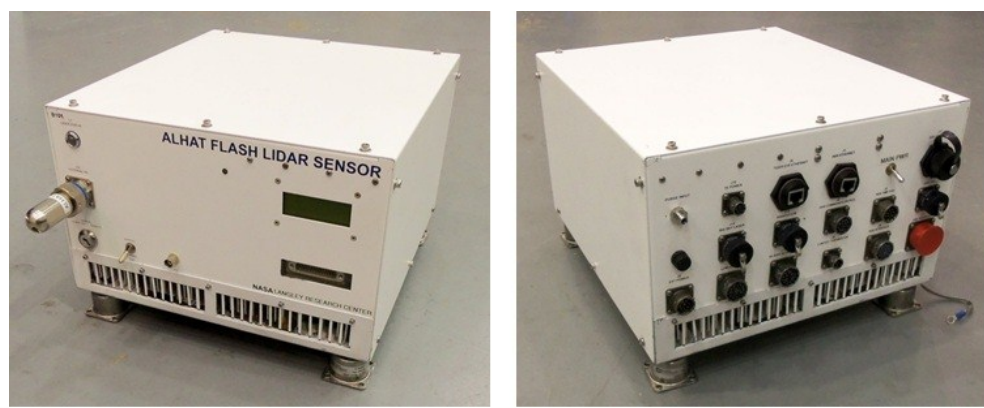

Figure 6. Gen 2.2 Flash Lidar Electronics Box (LEB) front and back. of operating in excess of $30 \mathrm{~Hz}$; however, the $20 \mathrm{~Hz}$ rate is compatible with the ALHAT navigation filter. The transmitter optics set the output divergence as needed to match the receiver lens selected for the flight. The receiver lens used for mosaic runs, with specifications in Table 3, is set for infinity focus while maximizing its depth of field (2 pixels of defocus verified at $250 \mathrm{~m}$ ). A $1^{\circ} \mathrm{FOV}$ receiver lens is chosen for a 128 by 128 pixel array to be operated starting from a slant range of $750 \mathrm{~m}$ for a GSD of $10 \mathrm{~cm}$. As is discussed in the flight results section, the actual operational range of the Flash Lidar exceeded the expected value by almost $50 \%$ due to the high reflectivity of the KSC sand that was available. The receiver lens Table 2. Gen 2.2 Flash Lidar payload specifications.

\begin{tabular}{|c|c|c|c|}
\hline Unit & $\begin{array}{c}\text { Size } \\
\text { (HxDxW) } \\
\text { Inches }\end{array}$ & Weight & $\begin{array}{c}\text { Power } \\
\text { Required } \\
\text { (average) } \\
\text { Watts }\end{array}$ \\
\hline $\begin{array}{c}\text { Flash Lidar Sensor } \\
\text { Head (FLSH) }\end{array}$ & $11 \times 13.5 \times 13.25$ & 35.5 & \\
\cline { 1 - 3 } $\begin{array}{c}\text { Flash Lidar Electronics } \\
\text { Box (LEB) }\end{array}$ & $9.5 \times 14.2 \times 13$ & 36 & \\
\hline
\end{tabular}
used for staring, superresolution runs is a LaRC-developed model detailed in Table 3 which is also set for infinity focus while maximizing its depth of field (1 pixel of defocus verified at $60 \mathrm{~m}$ ). The 3-D, imaging IR video camera, around which the entire system is designed, is the Advanced Scientific Concepts, Inc (ASC) Tiger Eye serial number $1005^{12}$. The heart of the Tiger Eye is its $128 \times 128$ pixel FPA sensor consisting of a hybridized detector based on Indium Gallium Arsenide-Avalanche Photodiode (InGaAs-APD) technology and ReadOut Integrated Circuit (ROIC) operating at a frame rate of $20 \mathrm{~Hz}$ (although it is capable of $30 \mathrm{~Hz}$ ). The GSD, which is the ground footprint of 1 pixel on a target at normal incidence, for both system lens configurations is detailed in Table 3 in addition to the maximum ground footprint of the entire FOV of the system. Note that the superresolution

Table 3. Gen 2.2 Flash Lidar instrument specifications.

\begin{tabular}{|c|c|c|}
\hline Parameter & $\begin{array}{c}\text { Mosaic } \\
\text { Configuration }\end{array}$ & $\begin{array}{c}\text { Staring } \\
\text { (superresolution) } \\
\text { Configuration }\end{array}$ \\
\hline Receiver lens FOV & $1.00 \mathrm{deg}$ & $4.85 \mathrm{deg}$ \\
\hline Aperture & $100 \mathrm{~mm}$ & $75 \mathrm{~mm}$ \\
\hline f/\# & 7.3 & 2 \\
\hline Number of pixels & \multicolumn{2}{|c|}{$128 \times 128$} \\
\hline $\begin{array}{c}\text { Ground footprint of entire FOV (at } \\
750 \mathrm{~m})\end{array}$ & $13 \mathrm{~m} \times 13 \mathrm{~m}$ & $63 \mathrm{~m} \times 63 \mathrm{~m}$ \\
\hline $\begin{array}{c}\text { GSD (at 750m): ground footprint } \\
\text { of 1 pixel }\end{array}$ & $10 \mathrm{~cm}$ & $50 \mathrm{~cm}$ \\
\hline Wavelength & \multicolumn{2}{|c|}{$1.064 \mu \mathrm{m}$} \\
\hline Pulse energy (Ep) & \multicolumn{2}{|c|}{$50 \mathrm{~mJ}$} \\
\hline Pulse width (FWHM) & $20 \mathrm{~Hz}(30 \mathrm{~Hz}$ capable) \\
\hline Frame rate & \multicolumn{2}{|c|}{} \\
\hline
\end{tabular}
technique is able to effectively reduce the GSD through real-time processing techniques in order to achieve the same apparent GSD as the mosaic configuration while imaging a considerable larger area, negating the need for a gimbal which could save considerable weight, power, and complexity. The mechanical support equipment for the sensor head consists of appropriate component mounting hardware, a base plate, gimbal mounting plates, metrology sphere nests, as well as a plastic, outer shell which serves as an aerodynamic shroud. The sensor head is actively air-cooled to minimize weight. A small optical witness camera is mounted on the belly of the sensor head to provide a wider-FOV context to help assess gimbal/lidar pointing performance.

The LEB houses the Flash Lidar electrical and software support equipment. The sensor controller, which serves as the control and data-handling hub of the Flash Lidar, is a PC-104 based subsystem running Linux and 
programmed in $\mathrm{C}++$. The sensor controller makes autonomous operations possible through communication with the external command and control source (the ALHAT HDS) and through communication with all key subsystems within the Flash Lidar. The sensor controller packages the 3D image data along with a time-

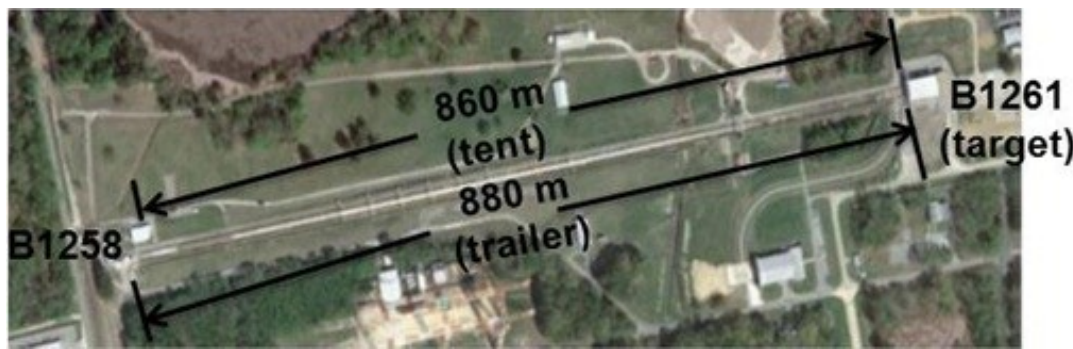

Figure 7. LaRC Long Distance Test Range (LDTR).

stamped header. The Vicor-based power conditioning and distribution system is controlled by the PCE (a microcontroller-based, LaRC-custom printed circuit board). The LEB also houses the thermal controllers and the Fibertek laser's electronics module.

The Flash Lidar sensor system interfaces with the ALHAT system through the NASA-Jet Propulsion Laboratory (JPL) led HDS and with the host vehicle system through the remote laser kill connection. The LEB mechanically interfaces to the host vehicle (19" rack tray in the present test) via isolation mounts. The FLSH mechanically interfaces to the HDS gimbal via side mount plates with the gimbal being mounted to the host vehicle via an adapter plate. A full series of thermal and vibration testing was accomplished based on the expected Morpheus environments which proved sufficient for helicopter operations as well. The electrical interfaces allow the Flash Lidar to operate autonomously. The inputs to the Flash Lidar include 28 VDC power, time synchronization signals, and commands. The Flash Lidar outputs real-time calibrated and corrected images as well as key telemetry data. The image calibrations, which will be discussed further in the lab characterization section, applied in real-time include a precision calibration and a range accuracy calibration. The real-time image

corrections applied include image filtering, dead pixel masking, and Automatic Gain Correction

(AGC). The AGC holds the image within the narrow dynamic range of the sensor for achieving the range precision goals. The

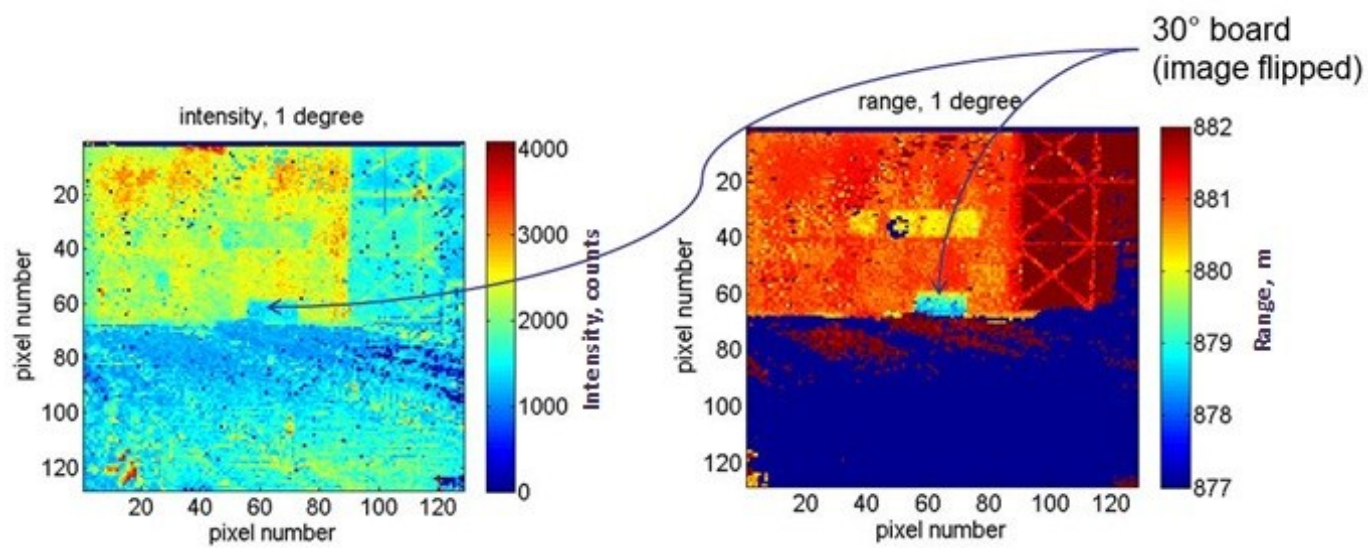
Figure 9. Maximum range testing on LaRC LDTR showing the $30^{\circ}$ LOS board at approximately $880 \mathrm{~m}$ with an intensity of 1500 counts (SNR of 1.5 ) from 3/8/2012 data with electronics box B1261 in the background. Note that the images are flipped horizontally.

has an interface option to allow for remote safety termination (killing) of the laser along with a confirmation return signal once the laser has indeed been killed. For the helicopter testing, a small user interface box (with indicator LED) was used by the on-board laser operator. 


\section{Lab Characterization}

The maximum operational range of the Flash Lidar was shown in lab testing to slightly exceed the present generation design goal of $750 \mathrm{~m}$ (just short of the long-term ALHAT goal of $1 \mathrm{~km}$ ) on a $30^{\circ}$ line-of-sight (LOS) target (giving a $60^{\circ}$ incidence angle) for a surface reflectivity at $1.06 \mu \mathrm{m}$ of $30 \%$ (referenced at normal incidence). Note that angle of incidence is measured from a normal to the surface. Maximum range testing is conducted on the LaRC Long Distance Test Range (LDTR). The building (B1261) on which the diffuse lidar targets are mounted is positioned approximately 880 meters from the trailer in which the lidar is

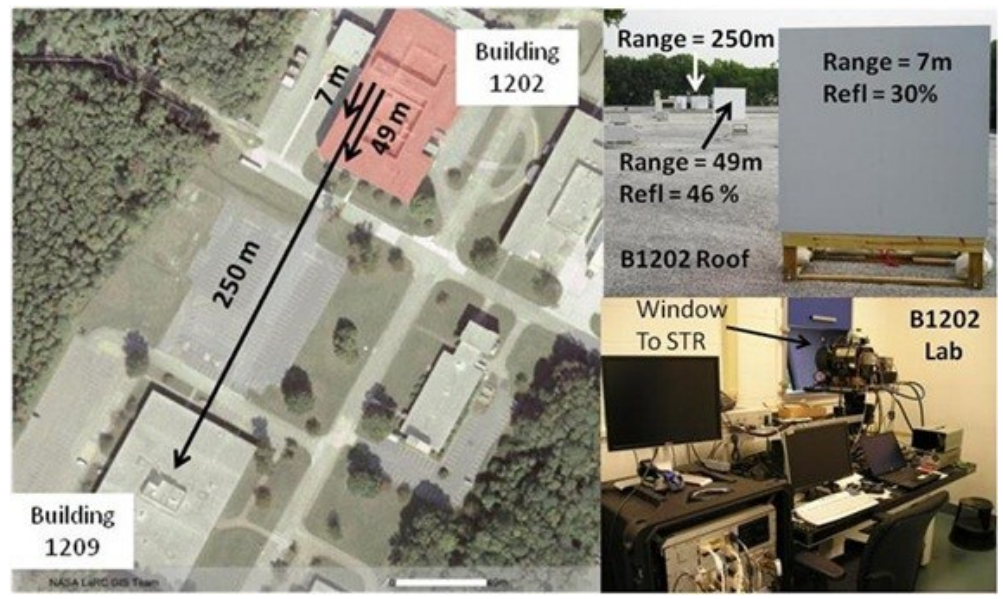

Figure 10. LaRC Sensor Test Range (STR) with target board at a range of $49 \mathrm{~m}$ used for range precision testing.

housed during testing. The target reflectivity choice of $30 \%$ is based on the reflectivity of sand from NASA-Dryden at $1.064 \mu \mathrm{m}$ since that is where much of the early lidar terrestrial flight testing has occurred. Maximum range testing at incidence angles typical of those resulting from the in-flight lidar look-angle in the maximum range portion of the approach trajectory is conducted by imaging a $30^{\circ}$ LOS flat, diffuse (nearly Lambertian) target board positioned against the LDTR target building. The angle of incidence affects maximum range performance since the intensity returns follow a cosine response function with a maximum at zero incidence. Figure 7 depicts the LDTR and locates key portions of the facility. Figure 8 shows the LDTR targets. During the maximum range testing, the camera sensitivity is set at its maximum while still suppressing extraneous backscatter so that no pixels are pretriggered falsely. Transmitter and receiver optics are the flight articles so that reflection and bulk absorption losses are indicative of those to be seen in flight. Laser divergence angle and receiver FOV are those to be used in flight, with the laser divergence slightly overfilling the receiver FOV to provide robustness against any misalignments which may occur as a result of the flight vibration and shock environment. The laser is held within its normal thermal operating range for a repeatable beam spatial profile and a pulse energy output of 50 millijoules $(\mathrm{mJ})$ emanating from the last transmitter optic. Figure 9 shows valid range data at $880 \mathrm{~m}$ on the LDTR $30^{\circ}$ LOS target with an intensity of 1500 counts. Based on a noise floor of 1000 counts, the signal-to-noise (SNR) ratio was 1.5. Trading excess signal (intensity) for range via the lidar equation ${ }^{13}$ places the maximum range at approximately 950 $\mathrm{m}$ with a SNR of 1.3. Data was acquired with the target at many points in the FOV and thus maximum range was set at SNR of 1.3 to provide margin for beam non-uniformities as well as for edge pixels which were designed to lose signal before the center pixels. 


\section{Range}

precision

essentially range

noise on an

image that can

serve to hide a

hazard which has

a size comparable

to the noise level.

As a reminder,

algorithm

simulations

indicate that a 5

$\mathrm{cm}$ range

precision coupled

with a $10 \mathrm{~cm}$ or

smaller GSD is

needed in order

to reliably

resolve $30 \mathrm{~cm}$

hazards ${ }^{3}$. Range

precision is one

standard

deviation

among

16,384
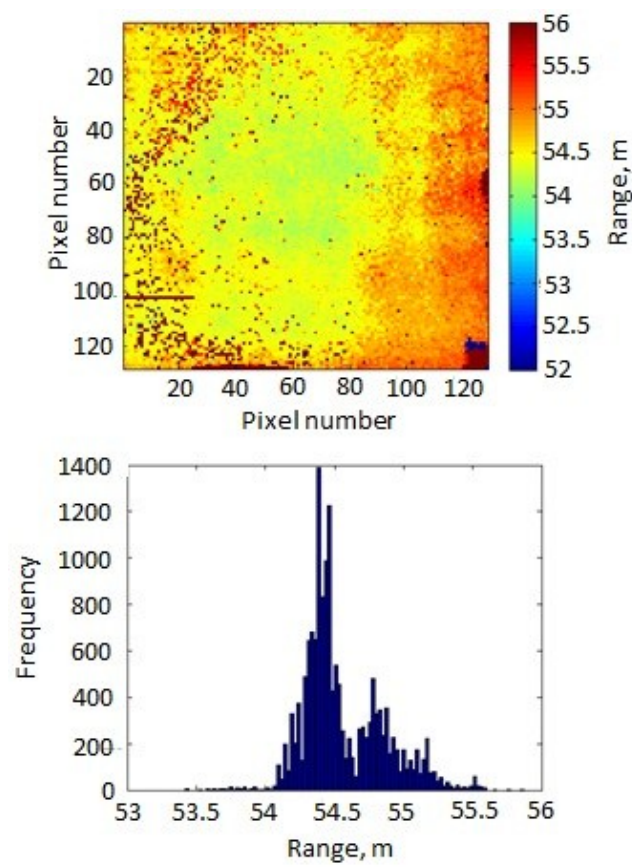

(a)
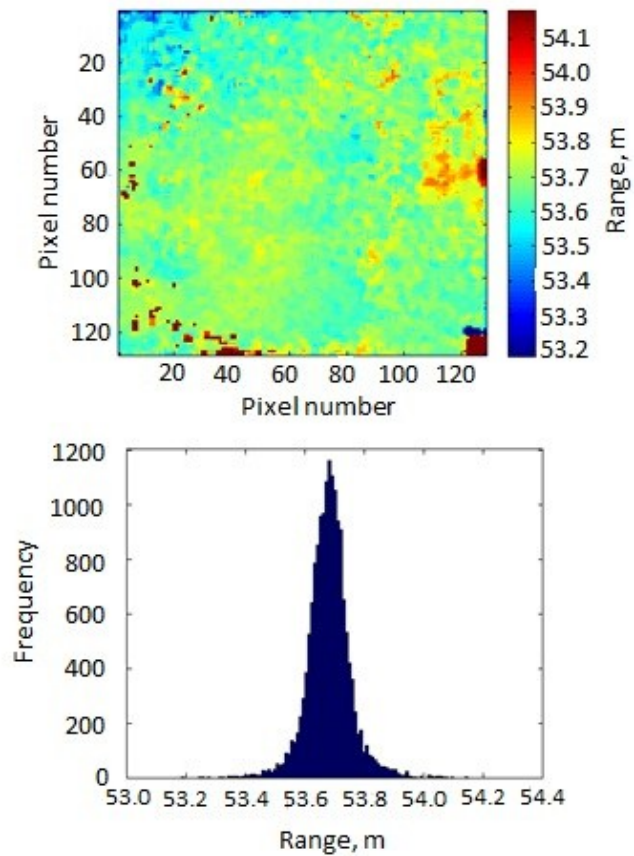

(b)

Figure 11. Effect of applying the precision calibration on short range $(50 \mathrm{~m})$ data from $11 / 1 / 2012, O D=3$ case. Range contour plot and related histogram before (a) and after (b) application of precision calibration showing flattening of the target board.

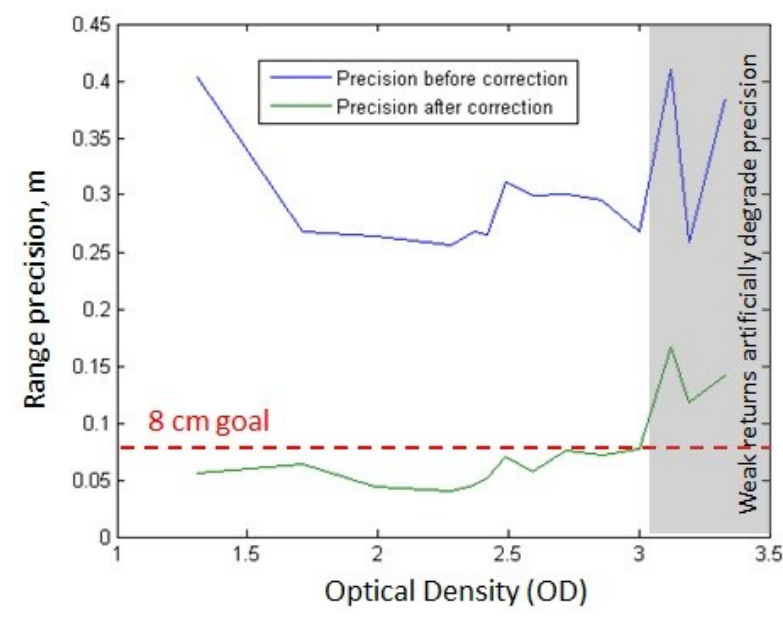

Figure 12. The $8 \mathrm{~cm}$ range precision goal is met (for short range, $50 \mathrm{~m}$ data) when the precision calibration is applied.

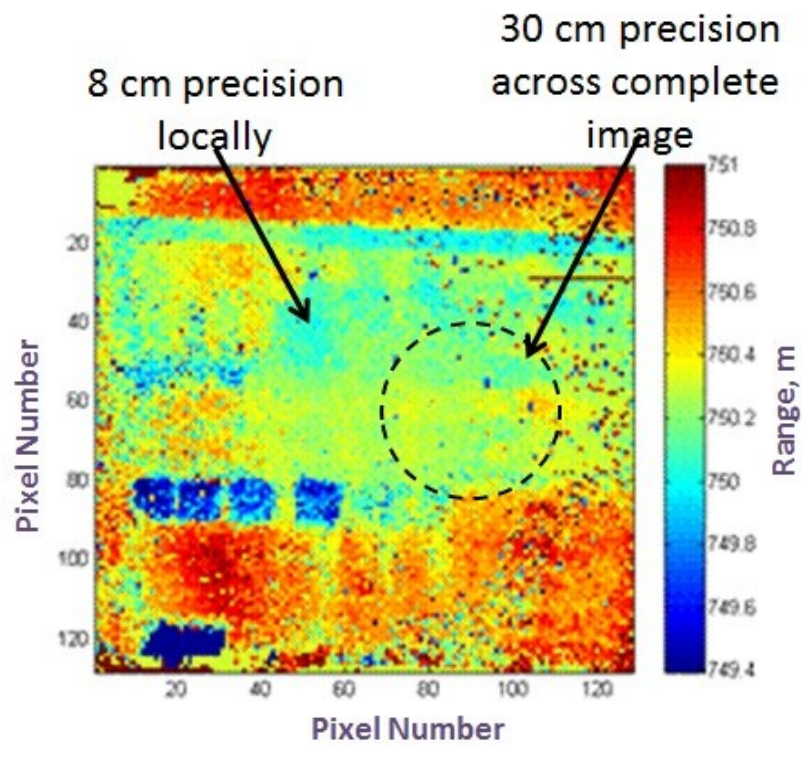

Figure 13. Range precision performance at long range $(750 \mathrm{~m})$ on flat portions of the LDTR B1261. Range precision is $30 \mathrm{~cm}$ across the image and $8 \mathrm{~cm}$ in local regions, thus only marginally meeting the goal.

within a single frame of range data. Calibrations are performed and embedded into the Flash Lidar in order to improve range precision. The calibration check is performed by imaging a flat target at normal incidence (so that 


\begin{abstract}
each pixel
should

report the

same

range to

target)

over a

span of

intensity

values.

The span

of

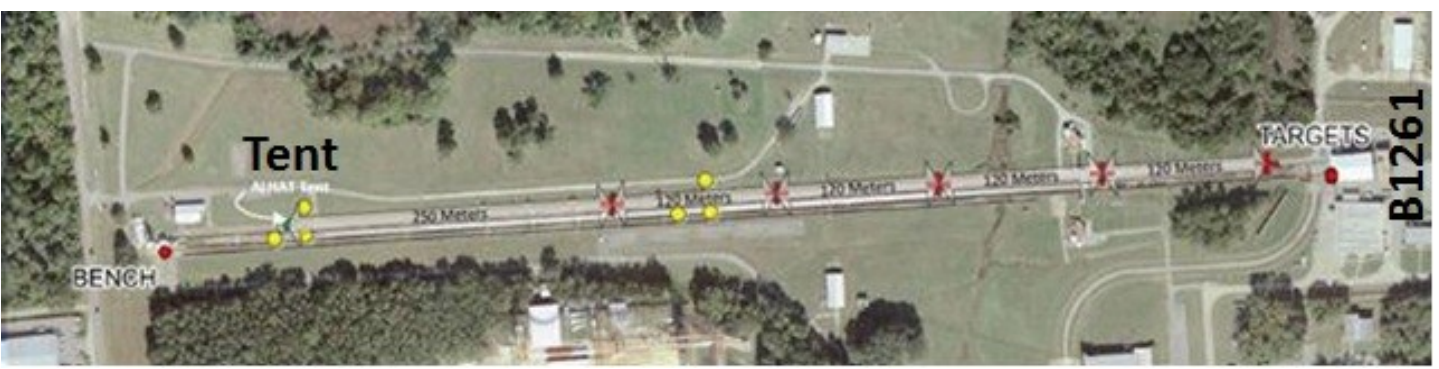

Figure 14. Flash Lidar accuracy calibration target layout on the LDTR with five targets from

intensity values is achieved by placing neutral density (ND) filters (which have a span of optical densities) over the laser output in order to vary the returning intensity over the full dynamic range of the sensor. The calibrations are applied in real-time.

An $8 \mathrm{~cm}$ range precision $(1 \sigma)$ is achieved (just short of the long-term ALHAT goal of $5 \mathrm{~cm}$ ) at short ranges while it is only marginally achieved at long ranges. The calibration check was performed on the LaRC Sensor Test Range (STR) $1.98 \times 1.98 \mathrm{~m}$ flat target board located normal to the lidar at a range of approximately $49 \mathrm{~m}$ as shown in Fig. 10 . A set of 14 ND filters was used that provided a span of optical densities (OD) from 1.33 to 3.33 . Figure 11 shows the range contour plots and their related histograms both before and after application of the range-intensity calibration. The range precision results over the full intensity span are shown in Fig. 12 for the short range $(50 \mathrm{~m})$ case. The figure indicates that the $8 \mathrm{~cm}$ range precision goal is met, except at the largest optical density (OD) values (smallest

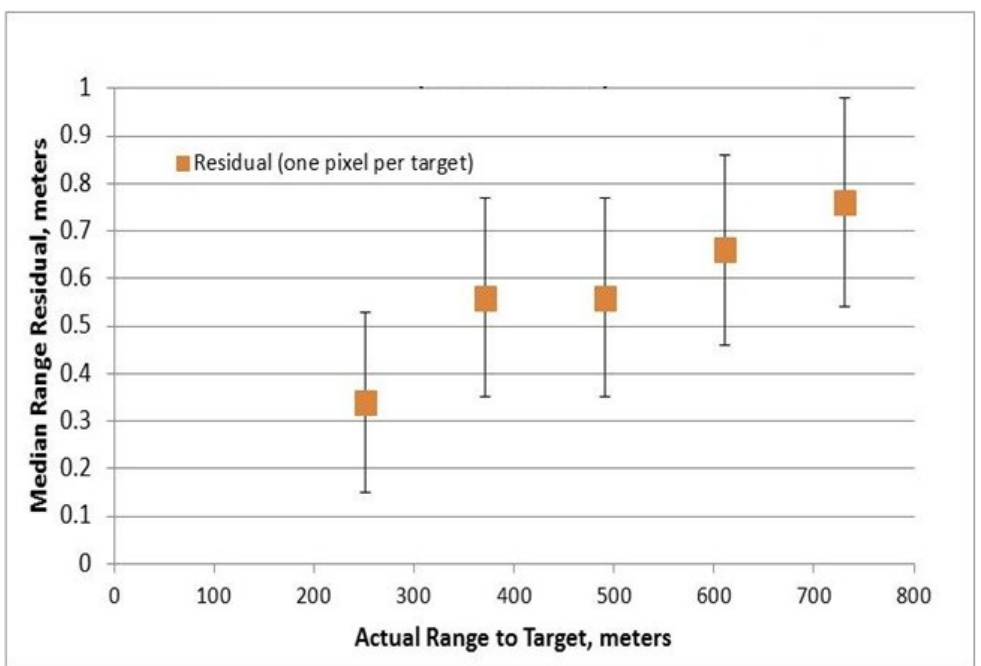

Figure 15. Range accuracy shown to be better than $1 \mathrm{~m}$ considering shot-to-shot variability over 30 frames at five discrete target distances situated along the full operational range of the Flash Lidar from 8/9/2012 data. Error bars show $\pm 1 \sigma$ uncertainty. intensity cases) where the larger number of un-triggered pixels (due to weak returns) contributes to larger perceived range precision. Figure 13 shows the range precision performance at long range on the LDTR $(750 \mathrm{~m})$ and how it falls short of the $8 \mathrm{~cm}$ precision goal. The $8 \mathrm{~cm}$ goal is achieved in local sections of the image, but low frequency spatial modes are present which result in range precision of approximately $30 \mathrm{~cm}$ over the image. Several possible solutions exist for improving the range precision performance including camera firmware upgrades calibration experiment modification. Modification of the calibration experiments since the time of the Gen 2.2 development and the present field test (FT5) has indeed resulted in $8 \mathrm{~cm}$ range precision for both short and long range.
\end{abstract}


A series of range accuracy calibration and verification tests are conducted on the LaRC LDTR. The Flash Lidar is situated in a tent on the LDTR and it images a set of five small 20 inch by 20 inch target boards situated at ranges to cover the operational range of the Flash Lidar $(250 \mathrm{~m}, 370 \mathrm{~m}$, $490 \mathrm{~m}, 610 \mathrm{~m}$, and $730 \mathrm{~m}$ ), as shown in Fig. 14.Figure 8 shows the longest range accuracy target situated at $730 \mathrm{~m}$. Each of the five targets is surveyed to a $2 \mathrm{~cm}$ accuracy to give known ranges from the

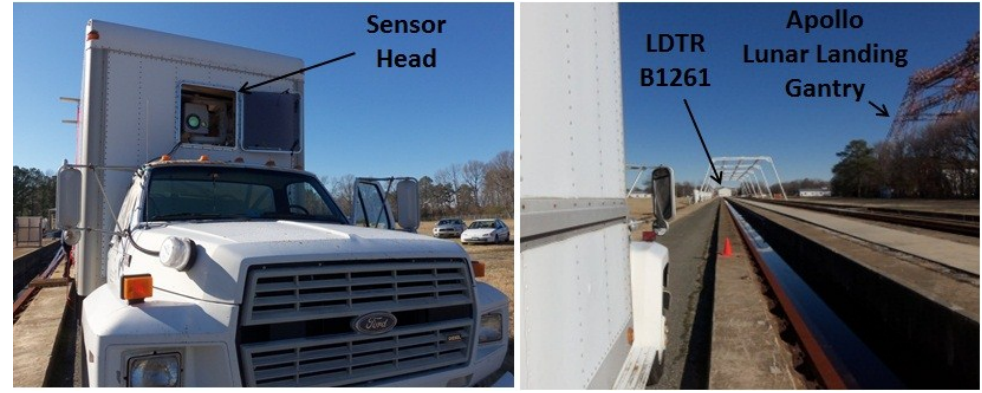

Figure 16. Flash Lidar during integrated ALHAT-Morpheus truck testing on the LaRC LDTR.

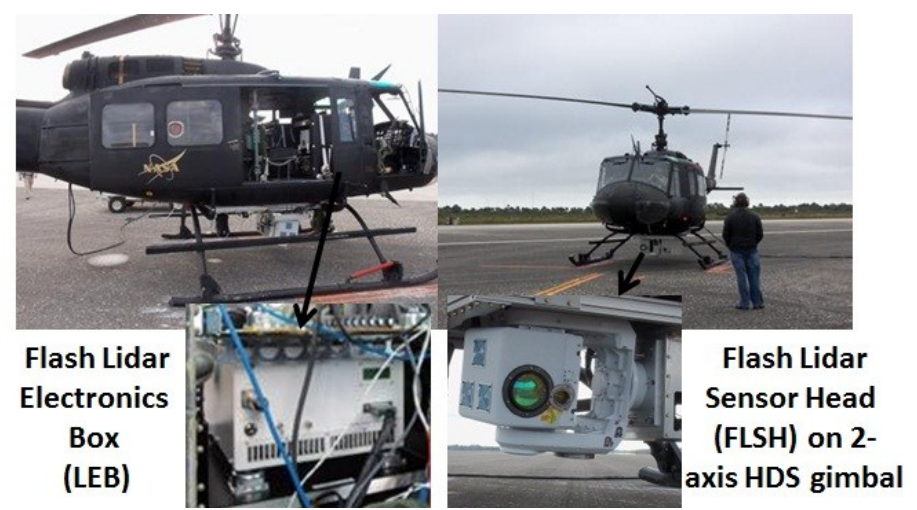

Figure 17. Flash Lidar integrated to LaRC UH-1H helicopter at rest on KSC Shuttle Landing Facility (SLF) runway.
Flash Lidar. Linear range accuracy calibration coefficients are computed from the accuracy testing and input into the Flash Lidar for application in real-time. To check the quality of the calibration, the calibration coefficients are loaded and the five targets are imaged again to check for accuracy performance. Figure 15 shows a plot of the median range residual for one pixel (at each of the five targets) over 30 frames. The error bars of Fig. 15 indicate plus and minus one standard deviation of the residual at each target which is mainly due to shot-to-shot variability caused primarily by t0 instabilities.

A series of metrology tests are conducted in the LaRC aircraft flight test hangar in order to map unit vectors for each of the lidar pixels in the sensor navigation reference frame by tying the pixel vectors to a set of metrology laser-alignment sphere nests which are hard (and permanently) mounted to the Flash Lidar sensor head at several locations as shown in Fig. 5. The details on the metrology tests are reported elsewhere ${ }^{9}$ The parafocal point, which lies along the optic axis on the front principle plane of the receiver lens, was used as a common point in all unit vector curve fits.

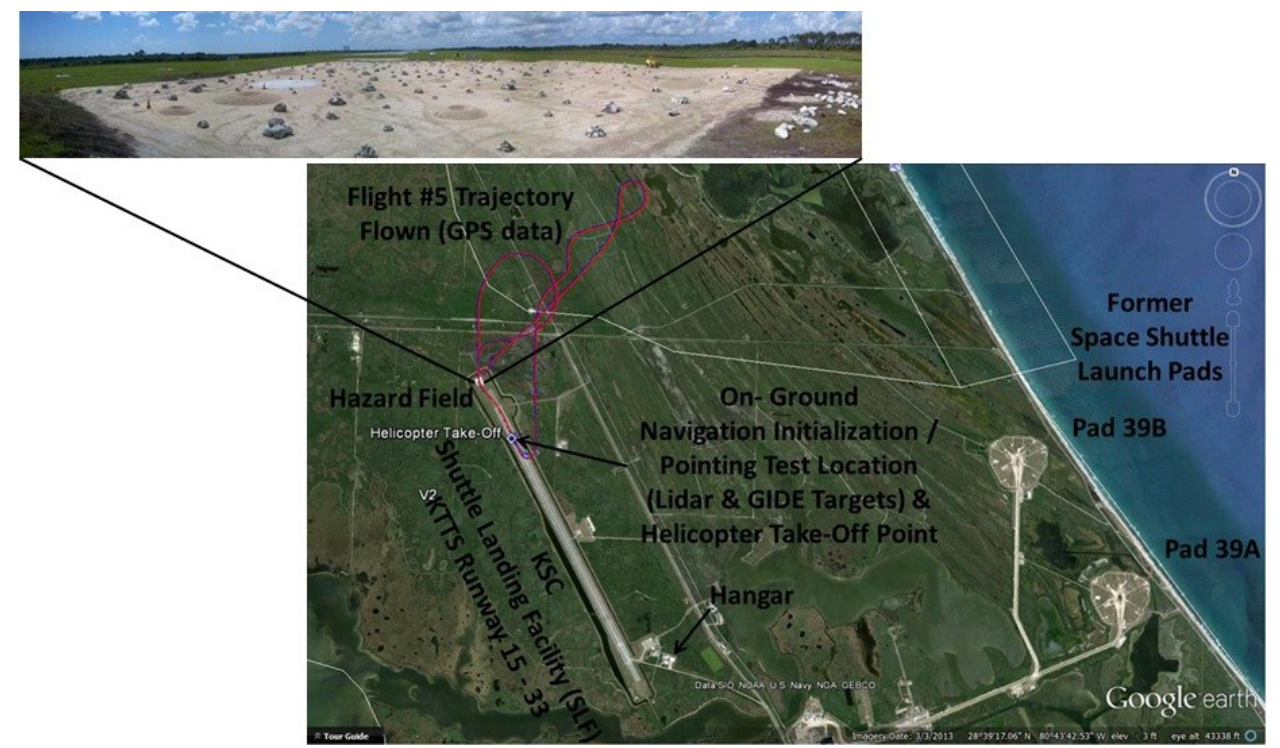

Figure 18. KSC overview locating the SLF with hazard field situated on the runway north end with flight $\# 5$ trajectory plotted. The hazard field with surveyed rock, crater, and slope hazards along with safe sites is shown in addition to the hangar staging facility and the on-ground navigation initialization point. 

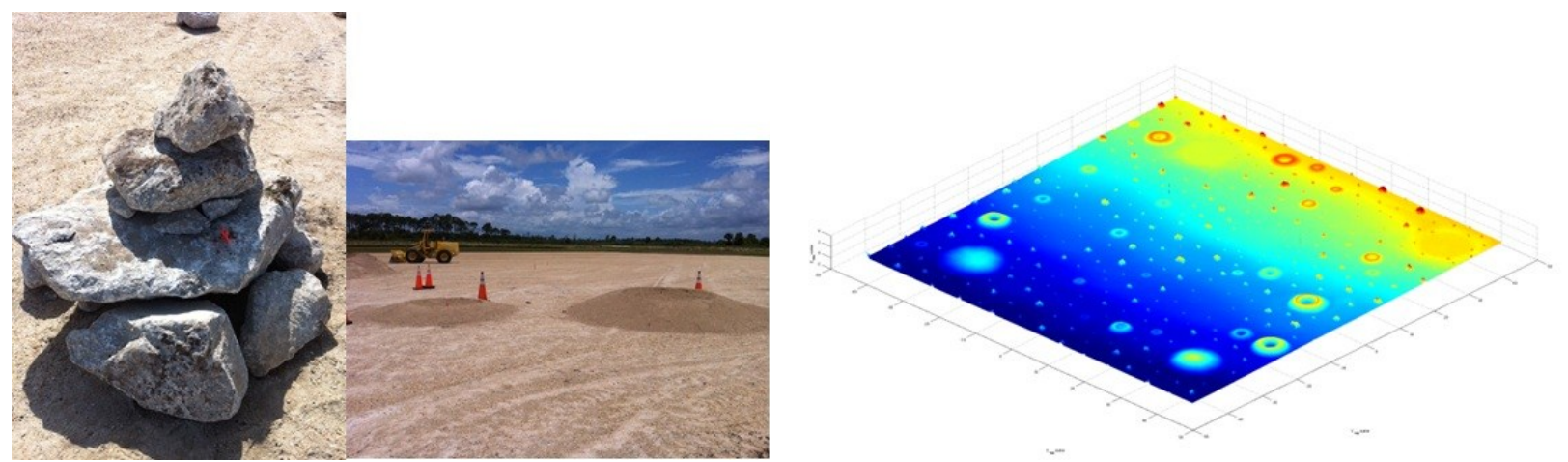

Figure 19. KSC hazard field rock (heights ranging Figure 20. Reference truth DEM of KSC hazard field from 30 to $100 \mathrm{~cm}$ ) and crater hazards. based upon survey data.

In preparation for full-system integration and testing on the UH-1H helicopter, the full ALHAT system along with the Morpheus navigation components to be flown were integrated into a truck and dynamically tested by members of the ALHAT and Morpheus teams at LaRC on the LDTR. The truck had been previously modified with a front window through which the lidar could point (see Fig. 16) without encountering truck structure to cause pretrigger backscatter issues. A driver and a system operator rode in the truck cab with the necessary control laptops and the remote laser kill box. The truck was driven down the LDTR toward the B1261 target building with the HDS tracking building targets using the Flash Lidar as well as accomplishing mosaics on the building. Pre-run navigation initialization was accomplished using the GIDE target (just as it was later done at KSC) and pre-run pointing quality assessment was done using the lidar targets

Table 4. Flight log of December 2012 testing.

\begin{tabular}{|c|c|c|c|c|}
\hline$\underset{\#}{\text { Flight }}$ & Date & $\begin{array}{l}\text { System } \\
\text { Config. }\end{array}$ & Profile & $\begin{array}{l}\text { \# of Ap- } \\
\text { proaches }\end{array}$ \\
\hline 1 & $\begin{array}{c}\text { Thurs, } \\
12 / 6 / 2012\end{array}$ & $1^{\circ}$ & $\begin{array}{c}30^{\circ} \text { track point } \\
\text { (hover } 500- \\
700 \mathrm{~m} \text { ) }\end{array}$ & 1 \\
\hline 2 & $\begin{array}{c}\text { Fri, } \\
12 / 7 / 2012\end{array}$ & $1^{\circ}$ & $\begin{array}{l}30^{\circ} \text { track point }(5) \\
/ \text { mosaic }(3)\end{array}$ & 8 \\
\hline 3 & $\begin{array}{c}\text { Sat, } \\
12 / 8 / 2012\end{array}$ & $1^{\circ}$ & $\begin{array}{l}30^{\circ} \text { track pt }(2) \\
30^{\circ} \text { mosaic }(3), 45^{\circ} \\
\operatorname{track} \text { pt }(1)\end{array}$ & 6 \\
\hline 4 & $\begin{array}{c}\text { Mon, } \\
12 / 10 / 2012\end{array}$ & $1^{\circ}$ & $\begin{array}{c}30^{\circ} \text { track point }(1) \\
30^{\circ} \text { mosaic }(4)\end{array}$ & 5 \\
\hline 5 & $\begin{array}{c}\text { Tues, } \\
12 / 11 / 2012\end{array}$ & $1^{\circ}$ & $30^{\circ}$ mosaic & 1 \\
\hline 6 & $\begin{array}{c}\text { Thurs, } \\
12 / 13 / 2012\end{array}$ & $1^{\circ}$ & $30^{\circ}$ mosaic & 1 \\
\hline 7 & $\begin{array}{c}\text { Thurs, } \\
12 / 13 / 2012\end{array}$ & $1^{\circ}$ & $30^{\circ}$ mosaic & 1 \\
\hline 8 & $\begin{array}{c}\text { Fri, } \\
12 / 14 / 2012\end{array}$ & $\begin{array}{c}5^{\circ} \\
\text { Superres. }\end{array}$ & $\begin{array}{c}30^{\circ} \operatorname{track} \operatorname{pt}(2), 45^{\circ} \\
\operatorname{track} \operatorname{pt}(1)\end{array}$ & 3 \\
\hline
\end{tabular}
on B1261 (just as it was later done at KSC).

\section{Helicopter Integration and Flight Test Plan}

The LaRC Flash Lidar is integrated with the remainder of the ALHAT GN\&C system (partners at JPL and JSC) as well as with key components of the Morpheus navigation system (partners at JSC) into the LaRC Bell UH-1H (N535NA) Iroquois "Huey" helicopter. The integrated systems are tested at LaRC before being deployed to KSC. Figure 17 shows the Flash Lidar components integrated on the UH-1H at KSC. The remainder of the ALHAT and Morpheus components is integrated to the helicopter either on a test fixture which is mounted to the UH-1H belly or to three small 19" racks in the cargo portion of the crew cabin. Note that the LaRC UH-1H is uniquely suited to belly-mounted installations since it has custom, experimental high-skids for landing which provide additional space not normally available under a UH-1H. Since the ALHAT systems are designed for autonomous operations onboard a Morpheus-like vehicle down to a single landing, multiple approaches on-board the UH-1H with minimal Morpheus navigation components available require the intervention of two ALHAT systems operators who flew onboard the UH-1H seated just aft of the equipment racks. 
ALHAT field test \#5 helicopter flight test operations consist of multiple approaches to a lunar-like hazard field. The helicopter is staged from a KSC hangar adjacent to the Shuttle Landing Facility (SLF) runway 15-33 shown in the lower portion of Fig. 18. The helicopter is first ferried to the opposite end of the SLF where it remains on the ground until the ALHAT and Morpheus navigation systems have completed initialization. After initialization, the ALHAT and Morpheus systems attempt to image two separate longrange targets, whose positions have been carefully surveyed, with the Flash Lidar in order to provide an end-to-end verification of total system pointing accuracy in preparation for airborne hazard detection runs. Once the pointing verification is completed, the helicopter takes off and flies one or more approaches starting from a 750 $\mathrm{m}$ slant range down

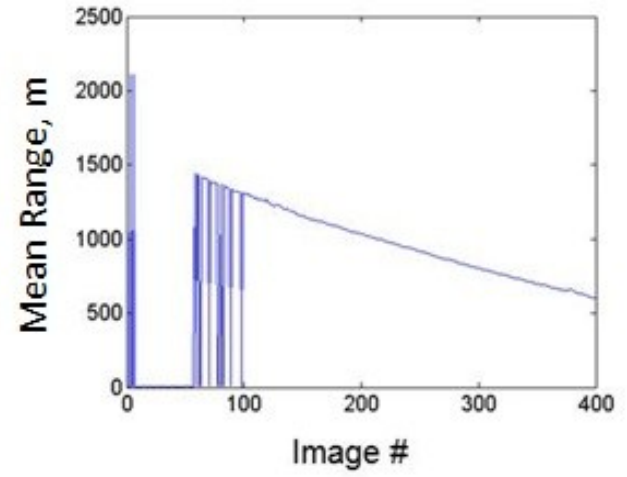

(a)

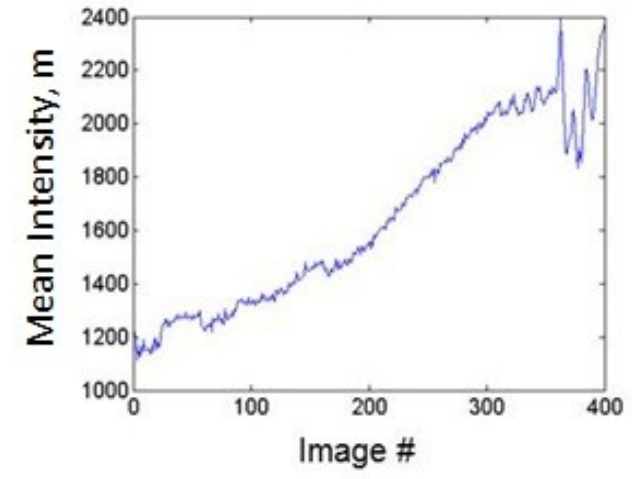

(b)

Figure 21. Flight \#3 mean slant range (a) and mean intensity (b) as a function of image number with every $5^{\text {th }}$ frame shown.

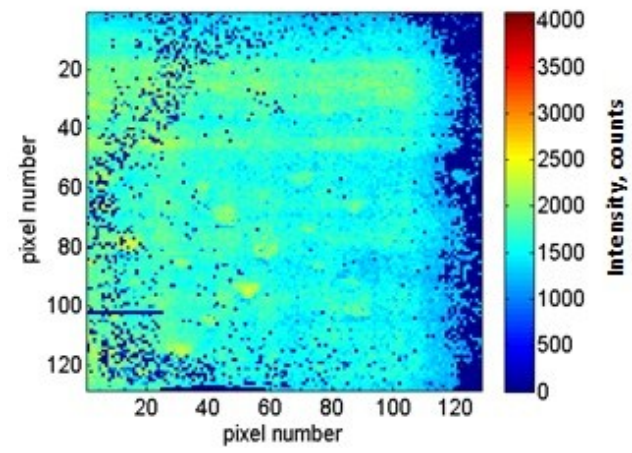

(a)

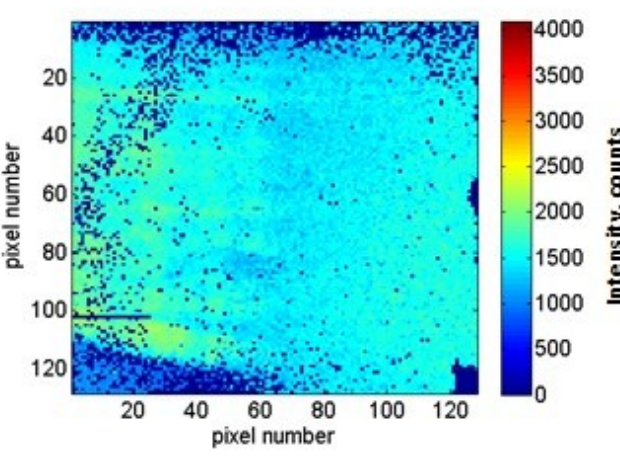

(c)

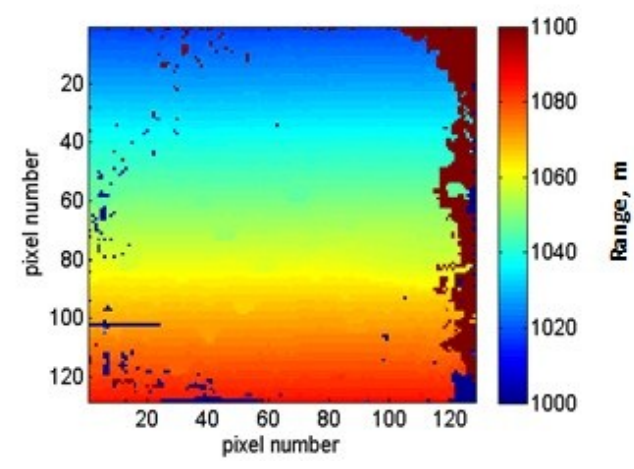

(b)

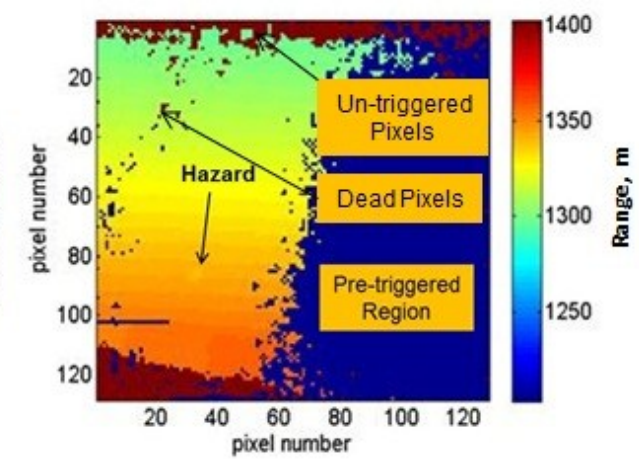

(d)

Figure 22. Intensity and range contour images of the KSC hazard field from approximately $1,000 \mathrm{~m}$ on flight $\# 2$ at $1038944962.087834 \mathrm{sec}$ (a, b) and $1,350 \mathrm{~m}$ on flight \#3 at $1039022573.625587 \mathrm{sec}(\mathrm{c}, \mathrm{d})$ at $30^{\circ}$ LOS. Un-triggered pixels are due to misalignment. Pre-triggering from near-field aerosols obscures part (c) and (d).

to a low approach over a $100 \mathrm{~m}$ by $100 \mathrm{~m}$ custom-built, hazard field consisting of lunar-like craters, rocks, slopes, and safe sites just off the north end of the SLF as shown in Fig. 18 and Fig. 19. Each hazard feature and safe site has been precision surveyed. Figure 20 shows a reference truth DEM generated based upon the hazard field highfidelity survey information for comparison against the in-flight generated ALHAT DEM's.

\section{Flight Test Results}

The December 2012 flight test campaign was conducted using the LaRC UH-1H helicopter flying approaches to the KSC hazard field. A total of eight flights were completed from December $6-14$ and are summarized in Table 


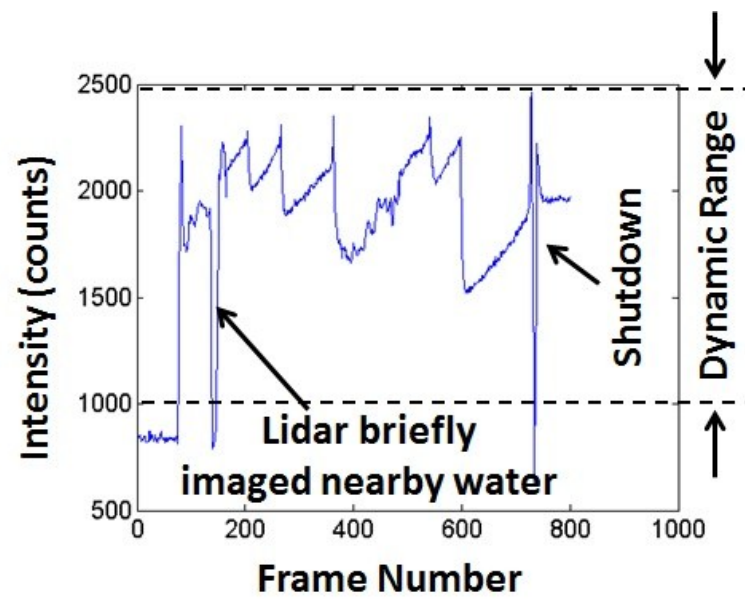

Figure 23. AGC holding the signal within the dynamic range during the flight $\# 5$ descent as slant range decreases threatening signal saturation.

4. The hazard field was imaged on the first seven flights using the mosaic technique (and thus 1 degree optics) while the final flight \#8 was conducted using the staring (superresolution) technique (thus using the 4.85 degree optics). The Flash Lidar met and exceeded the operational slant range goal $\left(250 \mathrm{~m}\right.$ to $750 \mathrm{~m}$ for $30^{\circ}+$ LOS targets), providing image data from $50 \mathrm{~m}$ to $1,350 \mathrm{~m}$ at $30^{\circ} \mathrm{LOS}$ with sharp 1-pixel focus above $250 \mathrm{~m}$. The Flash Lidar was able to resolve rocks as small as $25 \mathrm{~cm}$ from $1,050 \mathrm{~m}$ at $25^{\circ} \mathrm{LOS}$ based on visual analysis of range contour plots. The Flash Lidar provided calibrated and corrected images in real-time $(20 \mathrm{~Hz})$ to the HDS. Based on the Flash Lidar images, the HDS stitched together a mosaic of Flash Lidar range images, constructed a DEM of the landing area in near-real-time, and correctly found and reported safe sites during several of the flights. Remote laser safety termination was demonstrated for the lidar. Nearly autonomous operations were conducted (non-standard helicopter con-ops as compared to Morpheus con-ops resulted in some minimal required operator interaction) on a system significantly more compact in mass, power, and volume as compared to the Field Test \#4 system with on-board thermal control. The Flash Lidar systems survived the helicopter vibration environment. The weather during the test period included low cloud ceilings on most days which resulted in pre-triggering of the lidar on aerosols which was generally remedied by lowering the lidar sensitivity (except on flight \#8 during which the pretriggering was severe enough that it could only be suppressed for portions of each approach). Pretriggering refers to triggering of the affected lidar pixels on near-field aerosols rather than on the far field hazards resulting in effectively lost data (for the affected pixels only). Prior to the start of the test campaign, the Flash Lidar's transmitting and receiving optics

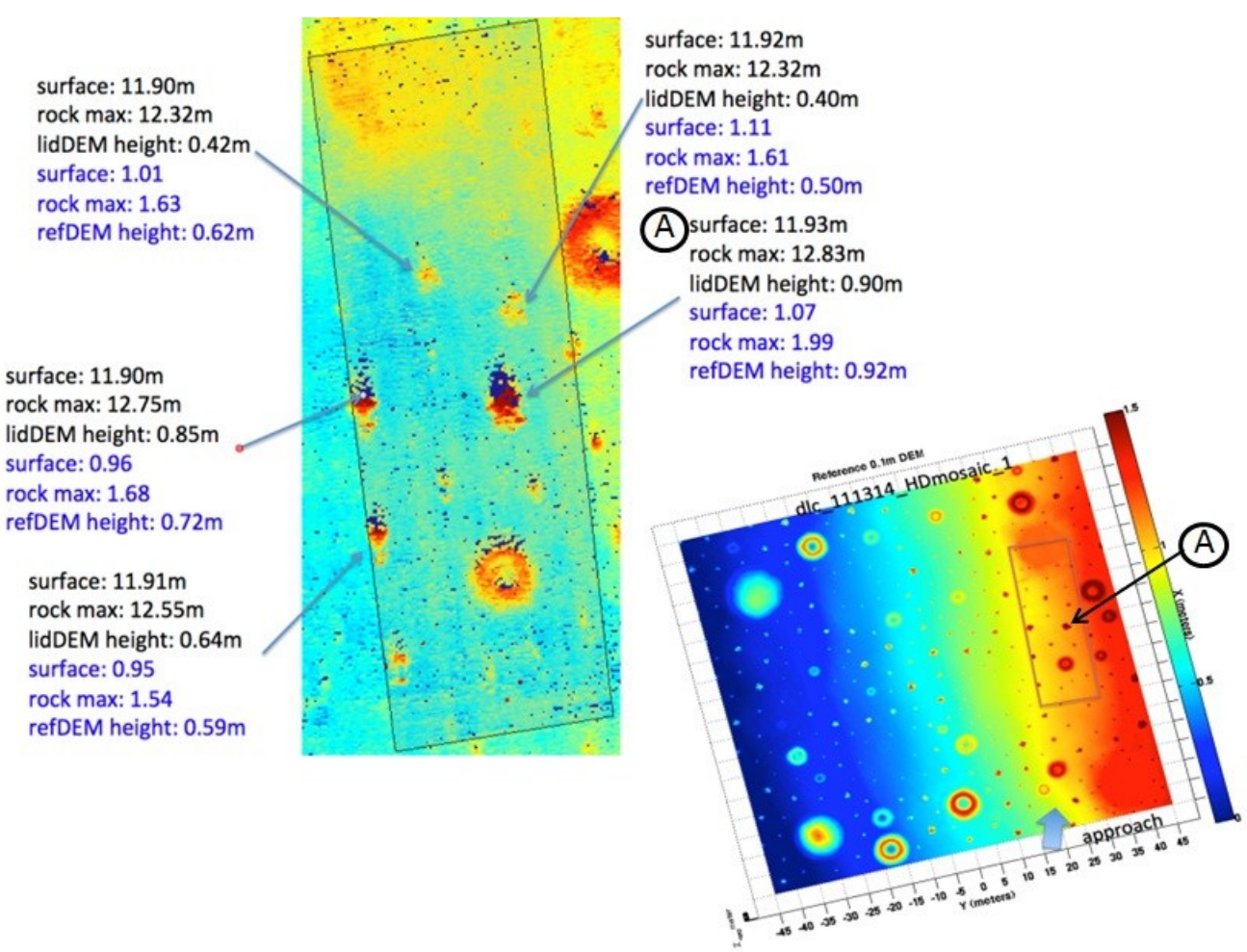

Figure 24. The effect on hazard distortion due to KSC hazard field reflectivities extending outside the Flash Lidar's dynamic range. Comparison of truth height (refDEM height) to lidar-inferred height (lidDEM height) for several KSC rock hazards from flight \#7 at 1039462366.685411 sec which extended outside the Flash Lidar's dynamic range shows little to no significant distortion.

became misaligned which resulted in two bands of un-illuminated (and hence un-triggered) pixels. During flights \#1 -4 , the un-triggered pixels reported the maximum range value of over $2000 \mathrm{~m}$, but for flights $\# 5-7$ these untriggered pixels were masked out so that they reported a range and intensity value of 0 for easier ingestion into the hazard detection algorithms of the HDS. The misalignment was corrected prior to flight \#8 and hence no pixels 
were masked out for flight \#8. The AGC results in a loss of five frames during each engagement (a situation known and characterized prior to the flights).

The maximum operational range of the Flash Lidar exceeded the $750 \mathrm{~m}$ requirement for the present generation. Figure 21 shows the mean slant range and mean intensity as a function of image number for one approach of flight \#2. Figure 22 shows intensity and range contour plots at a $30^{\circ} \mathrm{LOS}$ angle (corresponding to a $60^{\circ}$ incidence angle) from flight $\# 2$. Figure $22 \mathrm{a}$ and $22 \mathrm{~b}$ display intensity and range contour plots, respectively, from approximately $1,000 \mathrm{~m}$ with no pre-triggering (and a small strip of un-triggered pixels along the right edge due to a slight misalignment between the transmitter and receiver optics). Pre-triggering of pixels on cloud aerosols obscures half of the Fig. 22c and 22d images, but the other half of each image shows the hazard field at approximately $1,350 \mathrm{~m}$. The color gradient from bottom to top in each range image is due to apparent slope caused by the viewing angle. Applying the same SNR requirement of 1.3 as was applied in the lab characterization section, the maximum operational slant range achieved in the flight tests was $1,350 \mathrm{~m}$. The over-achievement in maximum range beyond the design goal is due to the high surface reflectivity of the KSC hazard field (approximately $60 \%$ for normal incidence at $1.06 \mu \mathrm{m}$ ) as compared to

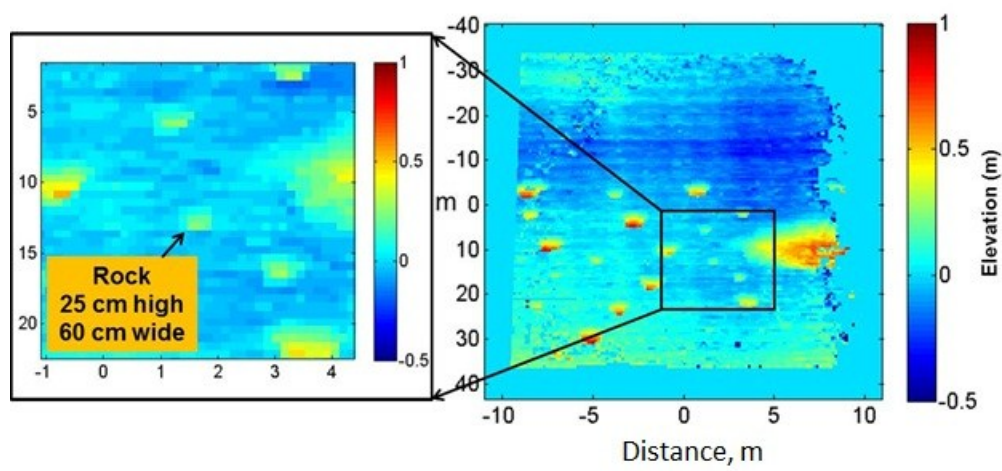

Figure 25: Flight \#2 lidar DEM from a $1,050 \mathrm{~m}$ slant range at $25^{\circ}$ LOS at 1038944961.487911 sec. with zoomed-in section showing the smallest visually detectable hazard $(25 \mathrm{~cm}$ high by $60 \mathrm{~cm}$ wide). The

the reflectivity used in design and development testing ( $30 \%$ for normal incidence at $1.06 \mu \mathrm{m})$. The Flash Lidar was designed and developed based on the $30 \%$ reflectivity value since it is typical of the California desert regions which are prime terrestrial test sites whose reflectivities are closer to that of the dark lunar surface than are those of the KSC hazard field.

The minimum operational range of the Flash Lidar is dominated by saturation and defocus. The Flash Lidar incorporates an AGC algorithm which can hold the image intensity within the sensor's dynamic range (e.g., Fig. 23) down to ranges of $50 \mathrm{~m}$. The Flash Lidar receiver lens is set for maximum depth of field in order to provide in-focus images at all ranges above $250 \mathrm{~m}$.

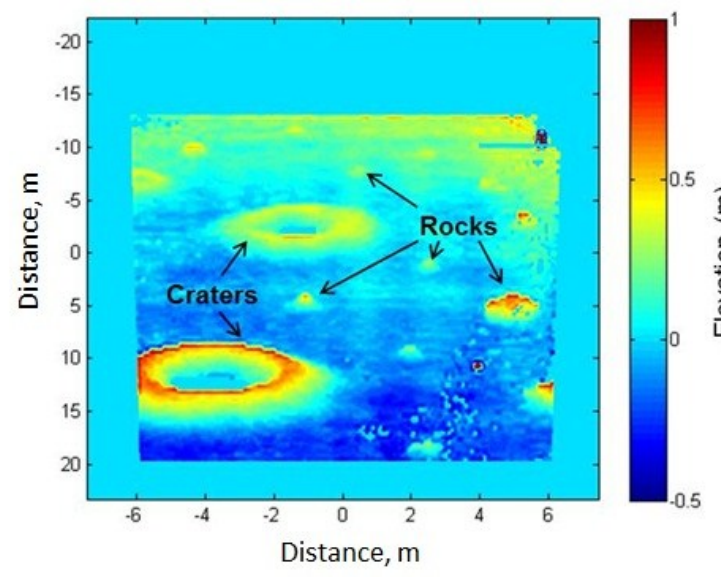

Figure 26. Flight \#7 lidar DEM at 1039462365.785527 sec. from a $700 \mathrm{~m}$ slant range at a $30^{\circ}$ LOS. Figure 24 shows several rock hazards imaged during flight $\$ 7$, most of which exceed the sensor's dynamic range and were saturated. The upper left of the figure shows a single frame of lidar data which has been converted to a DEM. For several rock hazards, the lidar-DEM-based height of the rock is compared to the truthDEM-based actual height of the rock. The lower right of the figure shows the orientation and placement of the Flash 
Lidar DEM under study in the context of the full hazard field on the truth DEM. Rock A is one example of a saturated rock. As the upper portion of the figure shows for rock A, as well as for all of the other rocks, no significant distortion occurs, i.e. all distortions are smaller than the $30 \mathrm{~cm}$ hazard resolution goal with all but one being a factor of 2 smaller.

As an example of the hazard detection capability of the lidar with $1^{\circ}$ optics installed for the mosaic mode, Fig. 25 shows a $25 \mathrm{~cm}$ high rock hazard that is visually identifiable from a slant range of 1,050m within one lidar frame. The figure shows a DEM which is constructed from a lidar range image along with a zoomed-in insert showing the $25 \mathrm{~cm}$ high rock hazard that is identifiable. For reference, the GSD at the range of Fig. 25 is $14 \mathrm{~cm}$. Figure 26 is a DEM constructed from one lidar frame from flight $\# 7$ which presents a host of crater and rock hazards.

As an example of the hazard detection capability of the lidar with $4.85^{\circ}$ optics installed for the staring, superresolution mode of flight \#8, Fig. 27 shows a set of rock hazards ranging in size from $20 \mathrm{~cm}$ to $1.3 \mathrm{~m}$ which are visually identifiable from a slant range of $400 \mathrm{~m}$. The superresolution algorithms were shown to be capable of imaging rocks as small as 40 $\mathrm{cm}$ from a slant range of $400 \mathrm{~m}$ representing a $4 \mathrm{x}$ digital magnification using 20 consecutive frames. Longer range images were not available on flight \#8 (the only flight with $4.85^{\circ}$ optics) due to low clouds and thick aerosols present that day causing pretriggering so significant that it could not be eliminated. Note that due to the larger FOV optics, a $34 \mathrm{~m}$ by $34 \mathrm{~m}$ area is imaged with a single lidar

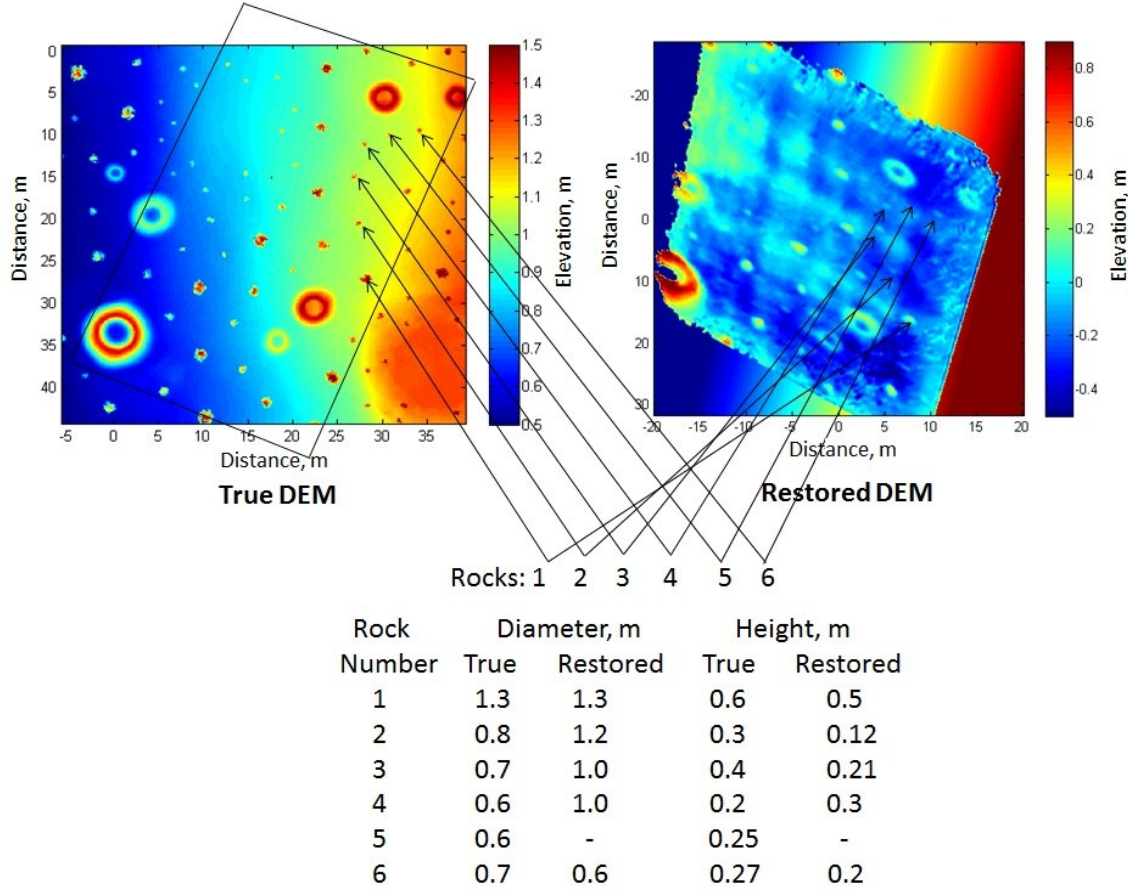

Figure 27. Superresolution algorithm imaging of hazards as compared to truth DEM using $4.85^{\circ}$ optics $(34 \mathrm{~m} \times 34 \mathrm{~m}$ ground coverage per shot) from $400 \mathrm{~m}$ at a $30^{\circ} \mathrm{LOS}$ in post-processing for a $4 \mathrm{x}$ magnification from 20 frames. frame almost negating the need for a gimbal to raster scan in order to see enough of the landing area to properly map it for safe sites. The image from the figure was not generated in real-time but was generated post-flight through onground processing of the actual flight data. In the time since the flights were concluded, a successful real-time demonstration during on-ground dynamic truck testing has occurred using an external General Purpose Graphics Processing Unit (GPGPU).

\section{Technology Advancement}

The present development and field test cycle has taken the Flash Lidar subsystem technology from Generation 2.1 (Gen 2.1) to Gen 2.2 and one step closer to achieving the long-range ALHAT goals en-route to attaining a TRL of 6 with the full, integrated ALHAT system. The system redesign in going from Gen 2.1 to Gen 2.2 resulted in considerable reduction in size, weight, and power consumption (SWaP) so that instead of equipment housed in 19" racks and two sensor heads, the complete system is contained in two small boxes. The SWaP improvements were not accompanied by performance degradation, but instead by performance enhancement including air-cooling, realtime image generation, autonomous operations capability, and incorporation of a remote laser safety termination system. Table 5 compares the achievements from the present development and test effort to the long-range ALHAT goals. The ALHAT maximum operational range goal at the $30 \%$ surface reflectivity value has been achieved, ignoring the $50 \mathrm{~m}$ difference which is on the order of experimental uncertainty. Through a combination of AGC (to balance signal drop-outs and saturation) and maximizing the receiver lens depth of field (to avoid excessive defocus with slant range), the minimum range goal of $100 \mathrm{~m}$ was achieved. A $128 \times 128$ pixel array camera was successfully 
demonstrated, however, a factor of Table 5. Summary of achievements from present development / test four additional pixels will ultimately cycle compared to ALHAT goals.

be needed in order to meet the GSD requirements for hazard detection at maximum range while still maintaining the FOV above $1^{\circ}$, to satisfy performance requirements for mosaicking. To accommodate the current state-of-the-art in FPA technology of a 128 by 128 pixel array (a factor of four smaller than the longterm ALHAT goal) in the present field test, the maximum operational range was limited to $750 \mathrm{~m}$ in order to achieve the required $10 \mathrm{~cm}$ GSD (that permits hazards of $30 \mathrm{~cm}$ or less to be

\begin{tabular}{|c|c|c|}
\hline Parameter & $\begin{array}{c}\text { Gen } 2.2 \\
\text { Achievements } \\
\text { (Field Test \#5) }\end{array}$ & $\begin{array}{c}\text { ALHAT } \\
\text { Long-Range } \\
\text { Goals }\end{array}$ \\
\hline \multirow{2}{*}{$\begin{array}{l}\text { Maximum Operational Range } \\
\left(30^{\circ} \text { line-of-sight target }\right)\end{array}$} & $\begin{array}{l}950 \mathrm{~m}(30 \% \\
\text { reflectivity) }\end{array}$ & \multirow{2}{*}{$\begin{array}{c}1,000 \mathrm{~m} \\
(30 \% \\
\text { reflectivity) }\end{array}$} \\
\hline & $\begin{array}{l}1,350 \mathrm{~m}(\sim 60 \% \\
\text { reflectivity })\end{array}$ & \\
\hline \# pixels & $128 \times 128$ & $256 \times 256$ \\
\hline Range precision & $8-30 \mathrm{~cm}^{*}$ & $5 \mathrm{~cm}$ \\
\hline Image calibration \& correction & Real-time & Real-time \\
\hline
\end{tabular}

detected) while still using a lens with FOV $\geq 1^{\circ}$ to satisfy mosaic performance requirements. In order to boost the maximum operational range, higher sensitivity camera FPA's are being pursued. Improved spatial precision (smaller GSD at longer ranges) is being pursued through prototype FPA's containing $256 \times 256$ pixels for maturation into full camera systems. Spatial precision improvement is also being pursed via a real-time image enhancement technique referred to as superresolution. The superresolution technique effectively increases the number of pixels by as much as a factor of 8 by combining successive images, each of which are shifted in space by either vehicle motion or vibration, in a way in which information between physical pixels is filled in. The superresolution technique could effectively give $256 \times 256$ pixel performance with a considerably larger FOV to cover more area in each shot of the lidar which could negate the need for a gimbal thus further reducing mass, power consumption, volume, and system complexity. Higher performance ROIC technology, advances in return signal processing firmware, and more robust calibration techniques are being evaluated for improving the range precision. Since the time of the present field test (FT5), improved calibration techniques have indeed resulted in $8 \mathrm{~cm}$ range precision performance over the full operational range of the Flash Lidar. Real-time output of fully calibrated and corrected images has been achieved in the present development and test cycle. Based on the Flash Lidar images, the HDS stitched together a mosaic of Flash Lidar range images, constructed a DEM of the landing area in near-real-time, and correctly found and reported safe sites during several of the flights.

The next field test will focus on closing the GN\&C loop through Morpheus free-flights in which the ALHAT system would direct Morpheus to safe-sites for actual landings on the same KSC hazard field approached during the present helicopter field test. The ALHAT systems have already undergone installation and interface testing on-board Morpheus (Fig. 28) as well as a series of low-altitude, powered flights

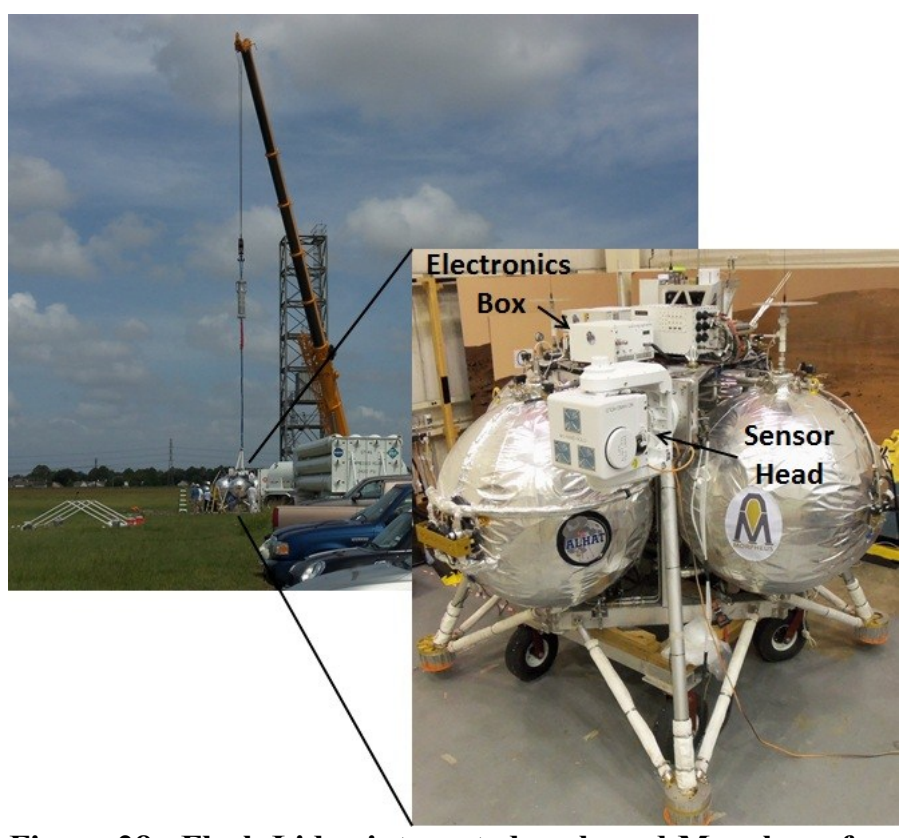

Figure 28. Flash Lidar integrated on-board Morpheus for a short flight at JSC while tethered to a crane during July 2013 in preparation for future free-flight testing at KSC during 2014.

at JSC in which Morpheus was tethered to a crane for added safety margin. The Morpheus vehicle (without ALHAT systems installed) is slated for a series of envelope expansion flights at KSC with ALHAT flights to follow in 2014. 


\section{Conclusion}

Flash Lidar technology is being evaluated by NASA to serve as the key hazard detection sensor in the GN\&C system for future robotic and crewed landers because of its ability to generate 3-D DEM's of the potential landing site in real-time for use in identifying hazardous craters, rocks and sloped terrain. Future missions will send landers to increasing complex sites (poorly lit, challenging terrain, etc.) on differing planetary bodies (moon, Mars, asteroids) due to the high scientific and mission payoff possible and will require them to do so with higher fidelity and safety. A Flash Lidar sensor system, developed from a number of cutting-edge components from industry and NASA, has been lab characterized and flight tested under the ALHAT project (in its fifth development and field test cycle) which is seeking to develop a GN\&C and sensing system based on lidar technology to carry out such missions. The Gen 2.2 Flash Lidar encompasses both SWaP reductions through compacting of the system into two small boxes and performance enhancements including air-cooling, real-time image generation and correction, autonomous operations capability, and incorporation of a remote laser safety termination system. The full ALHAT system along with select Morpheus navigation components were flown during December of 2012 in a UH-1H helicopter on multiple approaches to a custom lunar-like hazard field at KSC over the course of eight flights. In addition to providing the first opportunity to verify that all portions of the hazard field would fall within the Flash Lidar's dynamic range in preparation for future Morpheus robotic flights, the tests validated the lidar's operational range of $100 \mathrm{~m}$ to $1,350 \mathrm{~m}$, its ability to clearly image hazards as small as $25 \mathrm{~cm}$ from a slant range of $1 \mathrm{~km}$, and the lidar system's compatibility in flight with the avionics of the full ALHAT system and key portions of the Morpheus systems. The full ALHAT system in the $1^{\circ}$ optics configuration showed, for the first time in flight, its ability to generate near-real-time DEM's of the intended landing site along with correct safe-site locations amongst the many rock, crater, and slope hazards. In addition, through post-processing of the Flash Lidar images using the $4.85^{\circ}$ optics, the superresolution algorithms were shown to be capable of detecting rocks as small as $40 \mathrm{~cm}$ from a slant range of $400 \mathrm{~m}$ representing a $4 \mathrm{x}$ digital magnification. Although the Gen 2.2 Flash Lidar system has not yet fully achieved all of the long-term ALHAT goals, the current-generation system performance is guiding future Flash Lidar technology development to target higher-resolution focal plane arrays (256 x 256), an order-of-magnitude increase in the photon detection efficiency, and the improvement in range precision to less than $5 \mathrm{~cm}(1 \sigma)$. A followon field test, planned for 2014, seeks to complete the closing of the GN\&C loop for fully-autonomous operations onboard the Morpheus robotic, rocket-powered, free-flyer test bed in which the ALHAT system would scan the KSC hazard field (which was vetted during the present testing) and command the vehicle to an actual landing on one of the selected safe sites.

\section{Acknowledgments}

The authors would like to express appreciation to the ALHAT project manager, Chirold Epp of the NASA-Johnson Space Center, for his invaluable support. The authors are thankful to Advanced Scientific Concepts, Inc. for providing the Flash Lidar camera and for supporting the static and airborne tests. The authors acknowledge the ALHAT team members from the NASA-Jet Propulsion Laboratory for their collaboration on the HDS. The authors are thankful to the ALHAT and Morpheus team members at the NASA-Johnson Space Center for all of their efforts and support. The authors are thankful to the NASA-Langley flight operations team for providing the UH-1H helicopter. We would like to acknowledge Andres Huertas for generation of the lidar DEM and reference DEM of Fig. 24, Bill Carrion and Anna Noe for their support as master technicians, and Gregory Gaddis for facilitating the field test at NASA-Kennedy Space Center. We also would like to thank NASA's Advanced Exploration Systems (AES) program office for their continued support.

\section{References}

${ }^{1}$ Brady, T., and Paschall, S., "The Challenge of Safe Lunar Landing," Proceedings of the IEEE Aerospace Conference, IEEE, Piscataway, NJ, 2010, pp. 1-14.

${ }^{2}$ Epp, C.D., Robinson, E.A., and Brady, T., "Autonomous Landing and Hazard Avoidance Technology (ALHAT)", Proceedings of the IEEE Aerospace Conference, IEEE, Piscataway, NJ, 2008, pp. 1-7.

${ }^{3}$ Huertas, A., Johnson, A. E., Werner, R. A., Maddock, R. A., "Performance Evaluation of Hazard Detection and Avoidance Algorithms for Safe Lunar Landings," Proceedings of the IEEE Aerospace Conference, IEEE, Piscataway, NJ, 2010 , pp. 1 - 20.

${ }^{4}$ Amzajerdian, F., Pierrottet, D., Tolson, R. H., Powell, R. W., John B. Davidson, and Peri, F., "Development of a Coherent Lidar for Aiding Precision Soft Landing on Planetary Bodies," Proceedings of the $13^{\text {th }}$ Coherent Laser Radar Conference, Kamakura, Japan, 2005.

${ }^{5}$ Pierrottet, D., Amzajerdian, F., Petway, L., Barnes, B., and Lockard, G., "Flight test performance of a high precision navigation Doppler lidar," Proceedings of SPIE, Vol. 7323, SPIE, Bellingham, WA, 2009, pp. 11-1 - 11-9. 
${ }^{6}$ Amzajerdian, F., Pierrottet, D. F., Petway, L. B., Hines, G. D., Roback, V. E., and Reisse, R. A., "Lidar Sensors for Autonomous Landing and Hazard Avoidance," AIAA Space 2013 Conference, AIAA, Washington, DC (submitted for publication).

${ }^{7}$ Amzajerdian, F., Vanek, M., Petway, L., Pierrottet, D., Busch, G., and Bulyshev, A., "Utilization of 3-D Imaging Flash Lidar Technology for Autonomous Safe Landing on Planetary Bodies," Proceedings of SPIE, Vol. 7608, SPIE, Bellingham, WA, 2010, pp. 28-1-28-11.

${ }^{8}$ Roback, V. E., Bulyshev, A. E., Amzajerdian, F., and Reisse, R. A., "Helicopter Flight Test of 3-D Imaging Flash Lidar Technology for Safe, Autonomous, and Precise Planetary Landing," in Laser Radar Technology and Applications XVIII, edited by Monte D. Turner and Gary W. Kamerman, Proceedings of SPIE, Vol. 8731, SPIE, Bellingham, WA, 2013, pp. 87310H-1 $87310 \mathrm{H}-20$.

${ }^{9}$ Carson, J. M., Bailey, E. S., Trawny, N., Johnson, A. E., Roback, V. E., Amzajerdian, F., and Werner, R. A., "Operations Concept, Hardware Implementation and Ground Test Verification of a Hazard Detection System for Autonomous and Safe Precision Lunar Landing," AAS/AIAA 2013, AIAA, Washington, DC (submitted for publication).

${ }^{10}$ Trawny, N., Carson, J. M., Huertas, A., Luna, M. E., Roback, V. E., Johnson, A. E., Martin, K. E., and Villalpando, C. Y., "Performance of a Real-Time Hazard Detection System for Lunar Landing," AIAA Space 2013 Conference, AIAA, Washington, DC (submitted for publication).

${ }^{11}$ Bulyshev, A. E., Amzajerdian, F., Roback, V. E., and Reisse, R. A., "A Super-resolution Algorithm for Enhancement of FLASH LIDAR Data: Flight Test Results," IS\&T / SPIE Electronic Imaging 2014 Conference, SPIE, Bellingham, WA (submitted for publication).

${ }^{12}$ Stettner, R., "Compact 3-D Flash Lidar Video Cameras and Applications," Proceedings of SPIE, Vol. 7684, SPIE, Bellingham, WA, 2010, pp. 768405-1 - 768405-8.

${ }^{13}$ Wolfe, W. L. and Zissis, G. J., The Infrared Handbook, Infrared Information and Analysis (IRIA) Center, Michigan, 1985 , p. 23-6. 